\title{
Energetics of Syntrophic Cooperation in Methanogenic Degradation
}

\author{
BERNHARD SCHINK* \\ Fakultät für Biologie der Universität Konstanz, D-78434 Konstanz, Germany
}

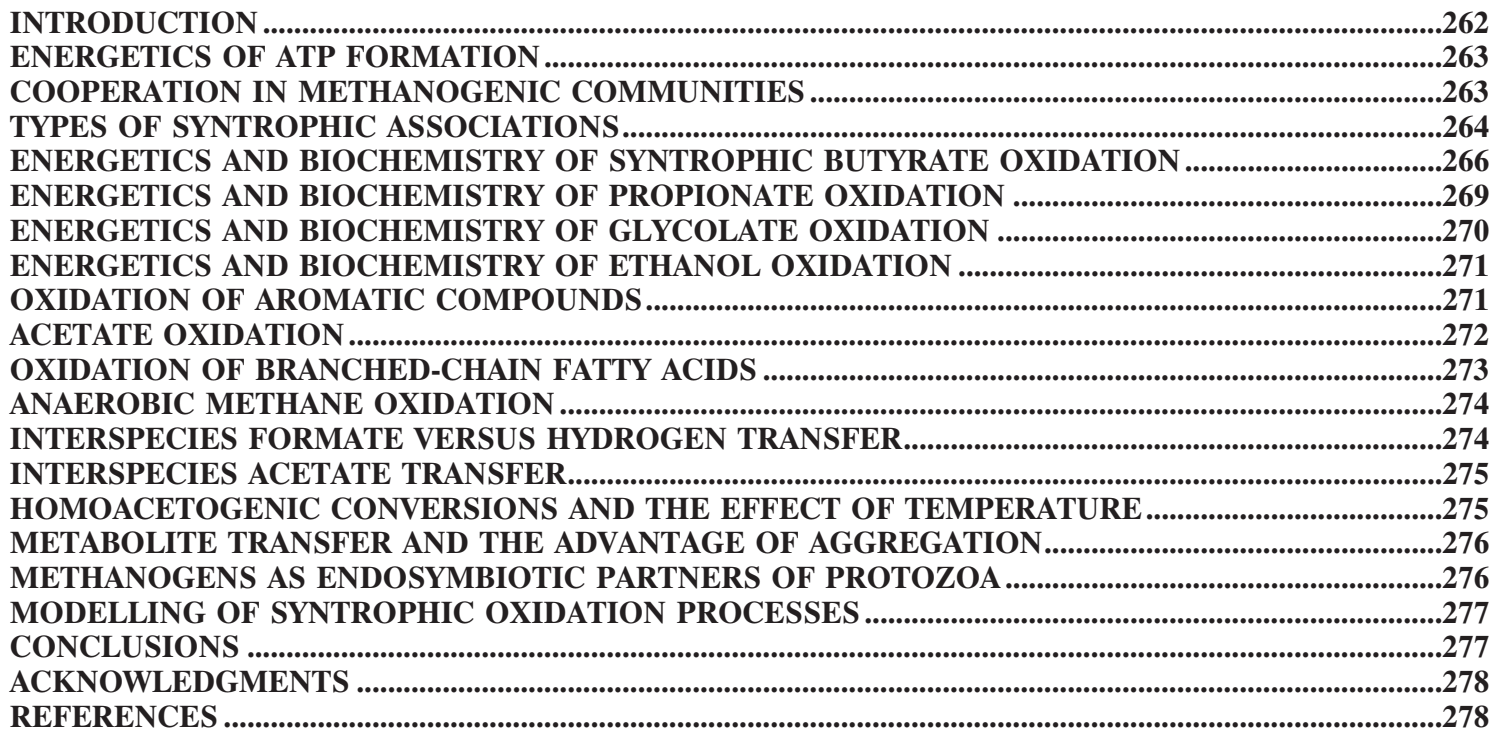

\section{INTRODUCTION}

The degradation of complex organic matter to methane and $\mathrm{CO}_{2}$ is a widespread process in anoxic environments which receive only a limited supply of oxygen, nitrate, sulfate, or oxidized iron or manganese species. It is the typical terminal electron-accepting process in freshwater sediments rich in organic matter, in swamps and waterlogged soils such as rice paddies, and in sewage treatment plants. Methanogenesis is also an important process in fermentations occurring in the intestinal tract of animals, especially ruminants. Methanogenic degradation is the least exergonic process when compared to aerobic degradation or the alternative anaerobic respirations. Conversion of hexose to methane and carbon dioxide releases only $15 \%$ of the energy that would be available in aerobic degradation,

$$
\begin{gathered}
\mathrm{C}_{6} \mathrm{H}_{12} \mathrm{O}_{6}+6 \mathrm{O}_{2} \rightarrow 6 \mathrm{CO}_{2}+6 \mathrm{H}_{2} \mathrm{O}\left(\Delta G^{\circ \prime}=-2,870 \mathrm{~kJ} \cdot \mathrm{mol}^{-1}\right) \\
\mathrm{C}_{6} \mathrm{H}_{12} \mathrm{O}_{6} \rightarrow 3 \mathrm{CO}_{2}+3 \mathrm{CH}_{4}\left(\Delta G^{\circ \prime}=-390 \mathrm{~kJ} \cdot \mathrm{mol}^{-1}\right)
\end{gathered}
$$

The low energy yield of methanogenic degradation as compared to that of the alternative oxidative processes may be the reason why methanogenesis is the last step to occur, after the other electron acceptors have been reduced. As a consequence of this small energy gain, the reaction product, methane, stores a major part of the energy available in aerobic biomass conversion. This energy can be exploited subsequently for energy in the presence of oxygen by other organisms, e.g., by aerobic

\footnotetext{
* Mailing address: Fakultät für Biologie der Universität Konstanz, Postfach 5560, D-78434 Konstanz, Germany. Phone: 49-7531-882140. Fax: 49-7531-882966. E-mail: bernhard.schink@uni-konstanz.de.
}

methane oxidizers or by humans in heating and other physical processes.

The small amount of energy available in methanogenic conversion forces the microorganisms involved into a very efficient cooperation. The mutual dependence of partner bacteria with respect to energy limitation can go so far that neither partner can operate without the other and that together they exhibit a metabolic activity that neither one could accomplish on its own. Such cooperations are called syntrophic relationships.

Syntrophism is a special case of symbiotic cooperation between two metabolically different types of bacteria which depend on each other for degradation of a certain substrate, typically for energetic reasons. The term was coined to describe the close cooperation of fatty acid-oxidizing, fermenting bacteria with hydrogen-oxidizing methanogens (77) or of phototrophic green sulfur bacteria with chemotrophic sulfur-reducing bacteria (11). In both cases, the pool size of the shuttling intermediate has to be kept small to allow efficient cooperation of both partner organisms.

The term "syntrophy" should be restricted to cooperations in which both partners depend on each other to perform the metabolic activity observed and in which the mutual dependence cannot be overcome by simply adding a cosubstrate or any type of nutrient. A classical example is the "Methanobacilus omelianskii" culture (6), which was later shown to be a coculture of two partner organisms, strain S and strain M.o.H. (18). The two strains cooperate in the conversion of ethanol to acetate and methane by interspecies hydrogen transfer, as follows:

$$
\begin{aligned}
& \text { Strain S: } 2 \mathrm{CH}_{3} \mathrm{CH}_{2} \mathrm{OH}+2 \mathrm{H}_{2} \mathrm{O} \rightarrow 2 \mathrm{CH}_{3} \mathrm{COO}^{-}+ \\
& 2 \mathrm{H}^{+}+4 \mathrm{H}_{2}\left(\Delta G^{\circ \prime}=+19 \mathrm{~kJ} \text { per } 2 \text { mol of ethanol }\right) \\
& \text { Strain M.o.H.: } 4 \mathrm{H}_{2}+\mathrm{CO}_{2} \rightarrow \mathrm{CH}_{4}+2 \mathrm{H}_{2} \mathrm{O}
\end{aligned}
$$




$$
\left(\Delta G^{\circ \prime}=-131 \mathrm{~kJ}\right. \text { per mol of methane) }
$$

Coculture: $2 \mathrm{CH}_{3} \mathrm{CH}_{2} \mathrm{OH}+\mathrm{CO}_{2} \rightarrow 2 \mathrm{CH}_{3} \mathrm{COO}^{-}+$

$2 \mathrm{H}^{+}+\mathrm{CH}_{4}\left(\Delta G^{\circ \prime}=-112 \mathrm{~kJ}\right.$ per mol of methane $)$

In this case, the fermenting bacterium cannot be grown with ethanol in the absence of the hydrogen-scavenging partner organism because it carries out a reaction which is endergonic under standard conditions. The first reaction can occur and provide energy for strain $\mathrm{S}$ only if the hydrogen partial pressure is kept low enough $(<100 \mathrm{~Pa})$ by the methanogen. Therefore, neither partner can grow with ethanol alone, and the degradation of ethanol depends on the cooperation of the two strains.

The dependence of the partner bacteria on each other has caused severe problems in the cultivation of such bacteria, and defined cocultures have been obtained only recently. For isolation, pure cultures of known methanogenic or sulfate-reducing partner bacteria are usually provided in excess as a background "lawn" during the cultivation and dilution process to isolate the syntrophically fermenting bacterium in defined binary or ternary mixed culture. Today, all well-described syntrophically fermenting bacteria can also be cultivated in pure culture with different substrate combinations (see below). Hence, we should no longer talk about "obligately syntrophic bacteria" (because they are not obligately syntrophic) but only about syntrophic relationships or syntrophic conversion processes.

I avoid in this article the term "consortium," which is quite often used to describe any kind of cooperating enrichment cultures. This term was originally coined for the structured phototrophic aggregates Pelochromatium and Chlorochromatium, etc., and is preferably used for such spatially well-organized systems $(83,123)$.

It is obvious from this introduction that energetic aspects are of special importance for an understanding of syntrophic cooperations in general. Earlier review articles have stressed this view quite convincingly $(17,30,74,75,95,97,109,135,136$, $142,144)$. The present overview focuses on the degradation of fatty acids, alcohols, and benzoate and will try to reexamine some of the earlier energetic concepts used in this field (118) in the context of recent advances in the microbiology and biochemistry of syntrophically fermenting bacteria. Details of the biology, cultivation, and isolation of these bacteria have been treated elsewhere $(95,109)$ or may be found in the original references given in these review articles.

\section{ENERGETICS OF ATP FORMATION}

Anaerobes operate with small amounts of energy, and syntrophically cooperating anaerobes have been found to be "experts" in the exploitation of minimal energy. The synthesis of ATP as the general currency of metabolic energy in living cells requires $+32 \mathrm{~kJ}$ per mol at equilibrium under standard conditions; under the conditions assumed to prevail in an actively growing cell $\left([\mathrm{ATP}]=10 \mathrm{mM} ;[\mathrm{ADP}]=1 \mathrm{mM},\left[\mathrm{P}_{\mathrm{i}}\right]=10 \mathrm{mM}\right)$, about $+50 \mathrm{~kJ}$ per mol is required (119). In addition, part of the total energy budget is always lost in irreversible reaction steps as heat, thus rendering the overall metabolic process irreversible. This heat loss (about $20 \mathrm{~kJ}$ per mol of ATP) has to be added to the above value, which gives a total of about $70 \mathrm{~kJ}$ per mol of ATP synthesized irreversibly in the living cell. This is the minimum amount of energy required for the synthesis of 1 mol of ATP by all known metabolic systems (94). One may argue that especially under conditions of energy limitation, an organism may waste less energy in heat production or that it may operate at a considerably lower energy charge than that quoted above for well-growing Escherichia coli cells. Nonetheless, one cannot expect that the energy requirement for irreversible ATP synthesis would be substantially lower than about $+60 \mathrm{~kJ}$ per mol.

The essential postulate of the Mitchell hypothesis of respiratory ATP synthesis is that ATP formation is coupled to a vectorial transport of charged groups, typically protons, across a semipermeable membrane (79). Today, it has been widely accepted that three protons cross the membrane per molecule of ATP hydrolyzed, no matter whether bacterial (71) or mitochondrial $(41,127)$ membranes are studied. As a consequence, the equivalent of one ATP unit is no longer regarded as the smallest quantum of energy a living cell can make use of. Actually, the smallest quantum of metabolically convertible energy is that of an ion transported across the cytoplasmic membrane, equivalent to one-third of an ATP unit. Combined with the above calculations, this means that a bacterium needs a minimum of about $-20 \mathrm{~kJ}$ per mol to exploit the free energy change in a reaction $(94,99)$. We will see that this is the amount of energy with which bacteria, cooperating in syntrophic fermentations, have to make their living.

\section{COOPERATION IN METHANOGENIC COMMUNITIES}

The conversion of complex organic matter, e.g., cellulose, to methane and carbon dioxide in a natural habitat is possible only by the concerted action of at least four different groups of bacteria, including primary fermenting bacteria, secondary fermenting bacteria, and two types of methanogens $(17,75,95$, $142,144,146)$. The degree of mutual dependence among these different bacterial types varies considerably; whereas the later members of the food chain always depend on the earlier ones for their substrates, they may also exert a significant influence on the earlier members in the chain by removing metabolic products. Polymers (polysaccharides, proteins, nucleic acids, and lipids) are first converted to oligomers and monomers (sugars, amino acids, purines, pyrimidines, fatty acids, and glycerol), typically through the action of extracellular hydrolytic enzymes. These enzymes are produced by the "classical" primary fermenting bacteria, which ferment the resulting monomers further to fatty acids, succinate, lactate, alcohols, etc. (Fig. 1, group 1). Some of these fermentation products, especially acetate, $\mathrm{H}_{2}, \mathrm{CO}_{2}$ and other one-carbon compounds, can be converted directly by methanogenic bacteria into methane and carbon dioxide (Fig. 1, groups 2 and 3). For degradation of other fermentation products, e.g., fatty acids longer than two carbon atoms, alcohols longer than one carbon atom, and branched-chain and aromatic fatty acids, a further group of fermenting bacteria, the so-called secondary fermenters or obligate proton reducers (Fig. 1, group 4), is needed. These bacteria convert their substrates to acetate, carbon dioxide, hydrogen, and perhaps formate, which are subsequently used by the methanogens.

The situation is slightly different in sulfate-rich anoxic habitats such as marine sediments. Also here, the primary processes of polymer degradation are carried out by primary fermenting bacteria which form the fermentation products mentioned above (Fig. 2, group 1). Different from methanogenic bacteria, sulfate-reducing bacteria are metabolically versatile, and a broad community of sulfate reducers can use all products of primary fermentations and oxidize them to carbon dioxide, simultaneously reducing sulfate to sulfide (133) (Fig. 2 , groups 2 to 4 ). As a consequence, complete oxidation of complex organic matter to carbon dioxide with simultaneous 

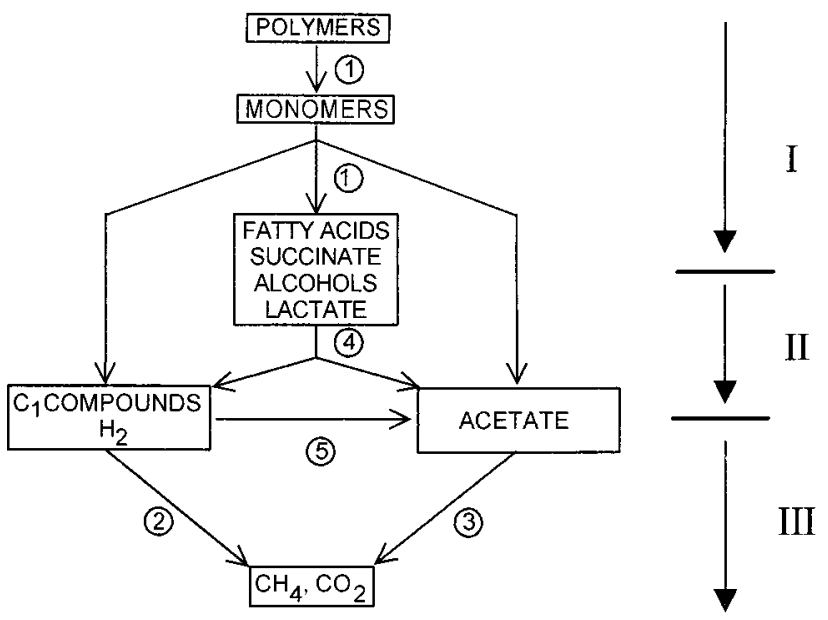

FIG. 1. Carbon and electron flow through the various trophic groups of microorganisms involved in the methanogenic degradation of complex organic matter in an anoxic freshwater habitat. Groups of bacteria involved: 1, primary fermenting bacteria; 2, hydrogen-oxidizing methanogens; 3, acetate-cleaving methanogens; 4, secondary-fermenting ("syntrophic") bacteria; 5, homoacetogenic bacteria. I, II, and III, steps in degradation. Based on reference 144; modified from reference 95 .

sulfate reduction is a two-step process and does not depend on syntrophic fermentations.

In methanogenic and sulfate-rich environments, the primary fermenting bacteria (group 1) profit from the activities of the hydrogen-oxidizing partners at the end of the degradation chain as well. A low hydrogen partial pressure $(<10 \mathrm{~Pa})$ allows electrons at the redox potential of NADH $(-320 \mathrm{mV})$ to be released as molecular hydrogen, and the fermentation patterns can shift to more acetate, $\mathrm{CO}_{2}$, and hydrogen production rather than ethanol or butyrate formation, thus allowing additional ATP synthesis. For example, Clostridium butyricum ferments hexose in pure culture roughly according to the following equation (119):

Glucose $+2 \mathrm{H}_{2} \mathrm{O} \rightarrow 0.7$ butyrate +0.6 acetate +

$1.3 \mathrm{H}^{+}+2 \mathrm{CO}_{2}+2.6 \mathrm{H}_{2}\left(\Delta G^{\circ \prime}=-233 \mathrm{~kJ}\right.$ per mol $)$

yielding 3.3 ATP units per glucose.

At $\left[\mathrm{H}_{2}\right]=10 \mathrm{~Pa}$, the overall reaction changes to

$$
\begin{gathered}
\text { Glucose }+2 \mathrm{H}_{2} \mathrm{O} \rightarrow 2 \text { acetate }+2 \mathrm{H}^{+}+2 \mathrm{CO}_{2}+4 \mathrm{H}_{2} \\
\left(\Delta G^{\prime}=-280 \mathrm{~kJ} \text { per mol }\right)
\end{gathered}
$$

yielding four ATP units per molecule of glucose, two in glycolysis and two in the acetate kinase reaction. Obviously, the bacteria balance the system to optimal energy exploitation because exactly $70 \mathrm{~kJ}$ is used for the synthesis of one ATP unit in both cases.

In a well-balanced anoxic sediment in which an active hydrogen-utilizing population maintains a low hydrogen partial pressure, the flux of carbon and electrons goes nearly exclusively through the "outer" paths of the flow schemes (Fig. 1 and 2), and reduced fermentation intermediates therefore play only a minor role. Nonetheless, the flux through the "central" paths will never become zero, because fatty acids, etc., are always produced in the fermentation of lipids and amino acids as well. The "central" reduced intermediates become more important if the hydrogen pool increases for any reason, e.g., excess supply of fermentable substrate and inhibition of hydrogenotrophic methanogens due to a drop in $\mathrm{pH}(<6.0)$ or to the presence of toxic compounds. Under such conditions, the pools of fatty acids increase and might even shift the $\mathrm{pH}$ further downward, thus inhibiting the hydrogenotrophic methanogens even further. The consequence may be that the whole system "turns over," meaning that methanogenesis ceases entirely and the fermentation stops with the accumulation of huge amounts of ill-smelling fatty acids, as is frequently encountered in ill-balanced anaerobic sewage digestors. Obviously, the hydrogen- and formate-utilizing methanogens act as the primary regulators in the total methanogenic conversion process $(17,142,144,146)$ and the syntrophically fatty acidoxidizing bacteria are affected most severely by a failure in methanogenic hydrogen or formate removal.

The function of homoacetogenic bacteria (Fig. 1, group 5) in the overall process is less well understood. They connect the pool of one-carbon compounds and hydrogen to that of acetate. Due to their metabolic versatility, they can also participate in sugar fermentation and degradation of special substrates such as $N$-methyl compounds or methoxylated phenols (96). In certain environments, e.g., at lower $\mathrm{pH}$ or low temperature, they may even successfully compete with hydrogenotrophic methanogens and take over their function to various extents (see below).

\section{TYPES OF SYNTROPHIC ASSOCIATIONS}

The above-mentioned case of "Methanobacillus omelianskii" is the classical example of interspecies hydrogen transfer. Both partners operate in an overall reaction process which is exergonic but becomes exergonic for the first partner only through maintenance of a low hydrogen partial pressure by the second partner. After description of the cooperative nature of this process, the original S strain was lost, but other syntrophically ethanol-oxidizing bacteria, such as Thermoanaerobium brockii (10) and various Pelobacter strains (39, 91, 92), have been isolated. Also, certain ethanol-oxidizing sulfate reducers such as Desulfovibrio vulgaris have proven to be able to oxidize ethanol in the absence of sulfate by hydrogen transfer to a hydrogen-oxidizing methanogenic partner bacterium (19).

Similar cooperations have been described with syntrophic

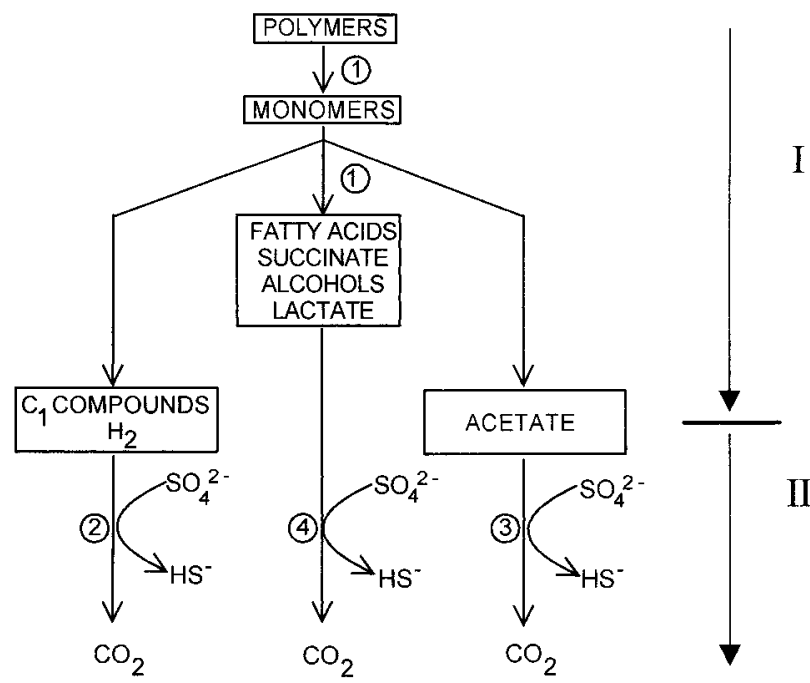

FIG. 2. Carbon and electron flow through the various trophic groups of microorganisms involved in sulfate-dependent degradation of complex organic matter in, e.g., a marine sediment. Groups of bacteria involved: 1, primary fermenting bacteria; 2 to 4 , sulfate-reducing bacteria. I and II, steps in degradation. Based on reference 133 . 
TABLE 1. Changes of Gibbs free energies under standard conditions in hydrogen-releasing and hydrogen-consuming reactions and corresponding redox potentials ${ }^{a}$

\begin{tabular}{|c|c|c|c|}
\hline Reaction & $\begin{array}{c}\Delta G^{\circ \prime} \\
(\mathrm{kJ} \text { per mol) }\end{array}$ & $\begin{array}{c}\text { No. of } \\
\text { electron pairs }\end{array}$ & $\begin{array}{l}\mathrm{E}^{\circ \prime} \text { of electron-releasing } \\
\text { redox reactions }(\mathrm{mV})\end{array}$ \\
\hline \multicolumn{4}{|l|}{ Hydrogen-releasing reactions } \\
\hline \multicolumn{4}{|l|}{ Primary alcohols } \\
\hline $\mathrm{CH}_{3} \mathrm{CH}_{2} \mathrm{OH}+\mathrm{H}_{2} \mathrm{O} \rightarrow \mathrm{CH}_{3} \mathrm{COO}^{-}+\mathrm{H}^{+}+2 \mathrm{H}_{2}$ & +9.6 & 2 & $-190,-375$ \\
\hline \multicolumn{4}{|l|}{ Fatty acids } \\
\hline $\mathrm{CH}_{3} \mathrm{CH}_{2} \mathrm{CH}_{2} \mathrm{COO}^{-}+2 \mathrm{H}_{2} \mathrm{O} \rightarrow 2 \mathrm{CH}_{3} \mathrm{COO}^{-}+2 \mathrm{H}^{+}+2 \mathrm{H}_{2}$ & +48.3 & 2 & $-125,-250$ \\
\hline $\mathrm{CH}_{3} \mathrm{CH}_{2} \mathrm{COO}^{-}+2 \mathrm{H}_{2} \mathrm{O} \rightarrow \mathrm{CH}_{3} \mathrm{COO}^{-}+\mathrm{CO}_{2}+3 \mathrm{H}_{2}$ & +76.0 & 3 & $+30,-176,-470$ \\
\hline $\mathrm{CH}_{3} \mathrm{COO}^{-}+\mathrm{H}^{+}+2 \mathrm{H}_{2} \mathrm{O} \rightarrow 2 \mathrm{CO}_{2}+4 \mathrm{H}_{2}$ & +94.9 & 4 & $-200,-300,-430,-520$ \\
\hline $\mathrm{CH}_{3} \mathrm{CH}\left(\mathrm{CH}_{3}\right) \mathrm{CH}_{2} \mathrm{COO}^{-}+\mathrm{CO}_{2}+2 \mathrm{H}_{2} \mathrm{O} \rightarrow 3 \mathrm{CH}_{3} \mathrm{COO}^{-}+2 \mathrm{H}^{+}+\mathrm{H}_{2}$ & +25.2 & 1 & \\
\hline \multicolumn{4}{|l|}{ Glycolic acid } \\
\hline $\mathrm{CH}_{2} \mathrm{OHCOO}^{-}+\mathrm{H}^{+}+\mathrm{H}_{2} \mathrm{O} \rightarrow 2 \mathrm{CO}_{2}+3 \mathrm{H}_{2}$ & +19.3 & 3 & $-92,-331,-470$ \\
\hline \multicolumn{4}{|l|}{ Aromatic compounds } \\
\hline $\mathrm{C}_{6} \mathrm{H}_{5} \mathrm{COO}^{-}+6 \mathrm{H}_{2} \mathrm{O} \rightarrow 3 \mathrm{CH}_{3} \mathrm{COO}^{-}+2 \mathrm{H}^{+}+\mathrm{CO}_{2}+3 \mathrm{H}_{2}$ & +49.5 & 3 & \\
\hline $\mathrm{C}_{6} \mathrm{H}_{5} \mathrm{OH}+5 \mathrm{H}_{2} \mathrm{O} \rightarrow 3 \mathrm{CH}_{3} \mathrm{COO}^{-}+3 \mathrm{H}^{+}+2 \mathrm{H}_{2}$ & +10.2 & 2 & \\
\hline \multicolumn{4}{|l|}{ Amino acids } \\
\hline $\mathrm{CH}_{3} \mathrm{CH}\left(\mathrm{NH}_{3}^{+}\right) \mathrm{COO}^{-}+2 \mathrm{H}_{2} \mathrm{O} \rightarrow \mathrm{CH}_{3} \mathrm{COO}^{-}+\mathrm{NH}_{4}^{+}+\mathrm{CO}_{2}+2 \mathrm{H}_{2}$ & +2.7 & 2 & $-115,-375$ \\
\hline \multicolumn{4}{|l|}{ Hydrogen-consuming reactions } \\
\hline $4 \mathrm{H}_{2}+2 \mathrm{CO}_{2} \rightarrow \mathrm{CH}_{3} \mathrm{COO}^{-}+\mathrm{H}^{+}+2 \mathrm{H}_{2} \mathrm{O}$ & -94.9 & & \\
\hline $4 \mathrm{H}_{2}+\mathrm{CO}_{2} \rightarrow \mathrm{CH}_{4}+2 \mathrm{H}_{2} \mathrm{O}$ & -131.0 & & \\
\hline $\mathrm{H}_{2}+\mathrm{S}^{\circ} \rightarrow \mathrm{H}_{2} \mathrm{~S}$ & -33.9 & & \\
\hline $4 \mathrm{H}_{2}+\mathrm{SO}_{4}{ }^{2-}+\mathrm{H}^{+} \rightarrow \mathrm{HS}+4 \mathrm{H}_{2} \mathrm{O}$ & -151.0 & & \\
\hline $\mathrm{H}_{2} \mathrm{C}\left(\mathrm{NH}_{3}^{+}\right) \mathrm{COO}^{-}+\mathrm{H}_{2} \rightarrow \mathrm{CH}_{3} \mathrm{COO}^{-}+\mathrm{NH}_{4}^{+}$ & -78.0 & & \\
\hline Fumarate $+\mathrm{H}_{2} \rightarrow$ succinate & -86.0 & & \\
\hline
\end{tabular}

${ }^{a}$ All calculations are based on published tables $(28,119)$. For $\mathrm{H}_{2} \mathrm{~S}$ and $\mathrm{CO}_{2}$, values for the gaseous state were used.

cultures degrading fatty acids. An overview of the reactions catalyzed is presented in Table 1; a list of strains of syntrophically fermenting bacteria follows in Table 2 . In general, degradation of fatty acids to acetate and hydrogen or, in the case of propionate, to acetate, hydrogen, and $\mathrm{CO}_{2}$ is far more endergonic under standard conditions than is the ethanol oxidation described above. Consequently, for fatty acid degradation, the hydrogen partial pressure has to be decreased to substantially lower values $(<10 \mathrm{~Pa})$ than with ethanol $(<100 \mathrm{~Pa})$.

A special case is the syntrophic conversion of acetate to $2 \mathrm{CO}_{2}$ and $4 \mathrm{H}_{2}$, which is catalyzed by a moderately thermophilic $\left(58^{\circ} \mathrm{C}\right)$ bacterium, strain AOR (149). This is a homoacetogenic bacterium which can either oxidize or synthesize acetate, depending on the external hydrogen concentration (see below).

Syntrophic oxidation of glycolate to $2 \mathrm{CO}_{2}$ was discovered only recently. Its energetic situation is comparable to that of ethanol oxidation. Also, aromatic compounds and amino acids can be oxidatively converted to acetate, $\mathrm{CO}_{2}\left(\right.$ and $\left.\mathrm{NH}_{4}{ }^{+}\right)$with concomitant interspecies hydrogen transfer to methanogenic partner bacteria.

On the side of hydrogen-consuming reactions, the function of methanogens can also be taken over by homoacetogenic, sulfur-reducing, sulfate-reducing, glycine-reducing, or fumarate-reducing bacteria (Table 1). Thus, the classical Stickland fermentation of pairs of amino acids can also be uncoupled and be carried out by two partner bacteria cooperating in interspecies hydrogen transfer. One partner oxidizes, e.g., alanine to acetate, $\mathrm{CO}_{2}, \mathrm{NH}_{4}{ }^{+}$, and hydrogen, and the other one uses hydrogen for the reduction of glycine to acetate:

$$
\mathrm{CH}_{3} \mathrm{CH}\left(\mathrm{NH}_{3}{ }^{+}\right) \mathrm{COO}^{-}+2 \mathrm{H}_{2} \mathrm{O} \rightarrow \mathrm{CH}_{3} \mathrm{COO}^{-}+
$$

$$
\begin{gathered}
\mathrm{CO}_{2}+\mathrm{NH}_{4}^{+}+2 \mathrm{H}_{2} \\
\left(\Delta G^{\circ \prime}=+2.7 \mathrm{~kJ} \text { per mol }\right) \\
\mathrm{CH}_{2}\left(\mathrm{NH}_{3}{ }^{+}\right) \mathrm{COO}^{-}+\mathrm{H}_{2} \rightarrow \mathrm{CH}_{3} \mathrm{COO}^{-}+\mathrm{NH}_{4}^{+} \\
\left(\Delta G^{\circ \prime}=-78 \mathrm{~kJ} \text { per mol }\right)
\end{gathered}
$$

Combined, the equations give

$$
\begin{gathered}
\mathrm{CH}_{3} \mathrm{CH}\left(\mathrm{NH}_{3}^{+}\right) \mathrm{COO}^{-}+2 \mathrm{CH}_{2}\left(\mathrm{NH}_{3}{ }^{+}\right) \mathrm{COO}^{-}+ \\
2 \mathrm{H}_{2} \mathrm{O} \rightarrow 3 \mathrm{CH}_{3} \mathrm{COO}^{-}+\mathrm{CO}_{2}+3 \mathrm{NH}_{4}^{+} \\
\left(\Delta G^{\circ \prime}=-151 \mathrm{~kJ} \text { per mol }\right)
\end{gathered}
$$

Thus, the electrons derived in amino acid degradation by a fermenting bacterium can be used in glycine reduction, as shown, but can also be transferred to sulfate-reducing, homoacetogenic, or methanogenic partner bacteria, depending on the availability of such partner bacteria and their respective electron acceptors. That amino acid oxidation and glycine reduction can be uncoupled from each other has been shown in detail with Eubacterium acidaminophilum (148). This bacterium can perform either of the first two reactions separately or combine them on its own, according to the third reaction, depending on the partner bacteria which act as hydrogen sources or sinks and on the availability in the medium of selenium, which is required for activity of the glycine reductase enzyme complex.

Efforts have been made to grow these syntrophically fermenting bacteria without partner bacteria. Removal of hydrogen by nonbiological procedures (low pressure or gas diffusion through thin membranes) had only little success with ethanol oxidation and no success at all with fatty acid oxidation. In other cases, hydrogen removal by palladium catalysts spread 
TABLE 2. Pure or defined cultures of bacteria catalyzing syntrophic substrate oxidations via interspecies hydrogen transfer, organized on the basis of the usual substrate

\begin{tabular}{|c|c|c|c|}
\hline Isolate & Substrate range & Gram type & Reference(s) \\
\hline Oxidation of primary alcohols & & - & \\
\hline Strain S & Ethanol & - & 18 \\
\hline Desulfovibrio vulgaris & Ethanol + sulfate & - & 19 \\
\hline Thermoanaerobium brockii & Ethanol, sugars, etc. & + & 10 \\
\hline Pelobacter venetianus & Ethanol, propanol & & 98 \\
\hline Pelobacter acetylenicus & Ethanol, acetylene & - & 92 \\
\hline Pelobacter carbinolicus & Ethanol, 2,3-butanediol & & 91 \\
\hline \multicolumn{4}{|c|}{ Oxidation of butyrate and higher homologs } \\
\hline Syntrophomonas wolfei & $\mathrm{C}_{4}-\mathrm{C}_{8}$ & - & 77,78 \\
\hline Syntrophomonas sapovorans & $\mathrm{C}_{4}-\mathrm{C}_{18}$ & - & 89 \\
\hline Syntrophospora bryantii & $\mathrm{C}_{4}-\mathrm{C}_{11}, 2$-methylvalerate & + & 114,147 \\
\hline Strains SF-1, NSF-2 & $\mathrm{C}_{4}-\mathrm{C}_{6}$ & + & 108 \\
\hline "Thermophilic coculture" & $\mathrm{C}_{4}$ & $?$ & 53 \\
\hline "Thermophilic coculture" & $\mathrm{C}_{4}$ & $?$ & 1 \\
\hline \multicolumn{4}{|l|}{ Oxidation of propionate } \\
\hline Syntrophobacter wolinii & Propionate & - & 14 \\
\hline Syntrophobacter pfennigii & Pyruvate & - & 130 \\
\hline Thermophilic coculture & Propionate + fumarate & - & 113 \\
\hline Strain MPOB & Propionate + fumarate & - & 33 \\
\hline \multicolumn{4}{|l|}{ Oxidation of acetate } \\
\hline Strain AOR & Acetate, ethanol, ethylene glycol & + & 66 \\
\hline Clostridium ultunense & Acetate, formate, cysteine & + & 103 \\
\hline \multicolumn{4}{|l|}{ Oxidation of isovalerate } \\
\hline Strain GraIva1 & Isovalerate only & + & 115 \\
\hline \multicolumn{4}{|l|}{ Oxidation of glycolate } \\
\hline Syntrophobotulus glycolicus & Glycolate, glyoxylate & + & 45,46 \\
\hline \multicolumn{4}{|l|}{ Oxidation of aromatic compounds } \\
\hline Syntrophus buswellii & Benzoate, crotonate & - & 81 \\
\hline Syntrophus gentianae & $\begin{array}{l}\text { Benzoate, gentisate, } \\
\text { hydroquinone }\end{array}$ & - & 131 \\
\hline Strain SB & Benzoate, crotonate & - & 56 \\
\hline
\end{tabular}

onto either charcoal or $\mathrm{CaCO}_{3}$ surfaces, with alkenes or alkines as oxidant, has shown some success (80), as have efforts to couple hydrogen release to reoxidation by electrochemically controlled platinum electrodes. More successful was the use of fumarate as an external electron acceptor in the cultivation of syntrophic propionate degraders (111). Today, pure cultures of syntrophically fermenting bacteria of all known metabolic types have been isolated. Typically, this has been accomplished with substrates that are more oxidized than the original one and can be fermented by dismutation. For example, ethanoloxidizing syntrophs can be grown in pure culture with acetaldehyde analogs such as acetoin or acetylene $(39,92)$, butyrateor benzoate-degrading syntrophs can be grown with crotonate $(7,131,147)$ or with pentenoate as an external electron acceptor (34), and syntrophically propionate-degrading bacteria can be grown with pyruvate (129) or propionate plus fumarate (111). Beyond that, all syntrophic propionate degraders have also been shown to be able to reduce sulfate and can be isolated in pure culture with propionate plus sulfate, although they are very slow growers with this substrate combination (49, $50,129,130)$.

Biochemical studies with defined cocultures of syntrophically fermenting bacteria have been carried out successfully with cell extracts prepared by, e.g., lysozyme (134) or mutanolysin (128) treatment, which lyses selectively only the fermenting bacterium and leaves the methanogenic partner intact, due to its archaeal cell wall chemistry. In another approach, the partner organisms were separated by centrifugation in Percoll gradients before being subjected to cell disruption and enzyme assays (9).

\section{ENERGETICS AND BIOCHEMISTRY OF SYNTROPHIC BUTYRATE OXIDATION}

The energetic situation of the partner bacteria involved in butyrate conversion to methane and $\mathrm{CO}_{2}$ is illustrated in Fig. 3 . The overall reaction

$$
2 \mathrm{CH}_{3} \mathrm{CH}_{2} \mathrm{CH}_{2} \mathrm{COO}^{-}+2 \mathrm{H}^{+}+2 \mathrm{H}_{2} \mathrm{O} \rightarrow 5 \mathrm{CH}_{4}+3 \mathrm{CO}_{2}
$$

yields, under standard conditions, a $\Delta \mathrm{G}^{\circ \prime}$ of $-177 \mathrm{~kJ}$ per $2 \mathrm{~mol}$ of butyrate. With concentrations more comparable to those prevailing in natural habitats, e.g., a freshwater sediment or a sewage sludge digestor (butyrate at $10 \mu \mathrm{M}, \mathrm{CH}_{4}$ at $0.7 \times 10^{5}$ $\mathrm{Pa} ; \mathrm{CO}_{2}$ at $\left.0.3 \times 10^{5} \mathrm{~Pa}\right)$, the free energy of this process changes to $-140 \mathrm{~kJ}$ per $2 \mathrm{~mol}$ of butyrate. This reaction is catalyzed by a community of three different bacteria which cooperate in seven independent partial reactions: butyrate conversion to acetate and hydrogen runs twice, $\mathrm{CO}_{2}$ reduction to methane runs once, and acetate cleavage to methane and $\mathrm{CO}_{2}$ runs four times. All these seven partial reactions have to yield ATP for the bacteria catalyzing them; they are specialists 


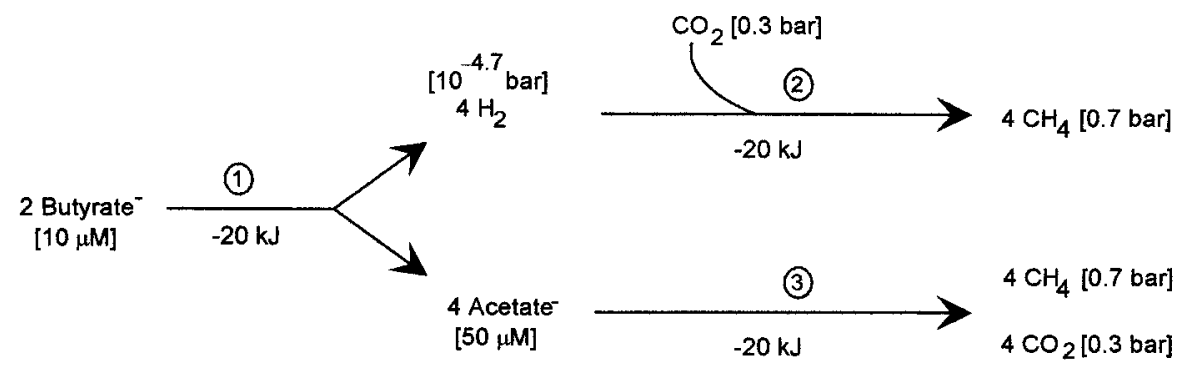

FIG. 3. Scheme of energy sharing among the three metabolic groups of prokaryotes cooperating in syntrophic butyrate degradation. See the text for an explanation. Modified from references 95 and 99.

for the respective reactions and depend on energy generation from them because they cannot switch to other types of energy metabolism. If we assume that they share the available energy in equal parts, the free energy change is about $-20 \mathrm{~kJ}$ per mol for every partial reaction. With these free energy values, the corresponding concentrations of the fermentation intermediates can be calculated, yielding around $2 \mathrm{~Pa}$ for hydrogen and $50 \mu \mathrm{M}$ for acetate. These values agree rather well with those measured in sediments or in digesting sludge (144). Thus, it appears reasonable to assume that the change in free energy of the total process is shared by all partial reactions in about equal amounts; this amount is in the range of the minimum energy quantum of about $-20 \mathrm{~kJ}$ per mol which can be exploited for ATP formation.

That the two methanogenic partners catalyze their reactions with energy yields in the range of one-third of an ATP unit is indicated by growth yield determinations under optimal conditions $(105,144)$ and also by our most recent understanding of the biochemistry of these bacteria $(12,26)$. Now the question arises of how the fermenting partner can manage its energy metabolism. The pathway of butyrate degradation in syntrophic butyrate-oxidizing bacteria has been elucidated with Syntrophomonas wolfei. It proceeds through classical $\beta$ oxidation via acetoacetyl coenzyme A ( CoA) and includes the formation of one ATP molecule through substrate-level phosphorylation (134) (Fig. 4). Since only a fraction of an ATP equivalent is available per reaction run under natural conditions (see above), part of this energy has to be reinvested into some other reaction.

In Fig. 5, redox potentials of the reaction pair $2 \mathrm{H}^{+} / \mathrm{H}_{2}$ at various hydrogen partial pressures are compared with standard potentials of the redox reactions involved in fatty acid oxidation (Table 1). It becomes obvious that oxidation of 3-hydroxybutyryl-CoA to acetoacetyl-CoA can be coupled to proton reduction at a hydrogen partial pressure close to $1 \mathrm{~Pa}$, similar to the value calculated above (Fig. 3). In contrast, proton reduction with electrons from butyryl-CoA oxidation would require a hydrogen partial pressure around $10^{-5} \mathrm{~Pa}$, a value which is far lower than has ever been observed in such cultures and which cannot be maintained by hydrogen-oxidizing methanogens: hydrogen-dependent $\mathrm{CO}_{2}$ reduction reaches thermodynamic equilibrium at $0.2 \mathrm{~Pa}$ of $\mathrm{H}_{2}$ (with 1 bar $\mathrm{CO}_{2}$ ). For this reason, it was postulated (118) that this step involves a reversed electron transport system which shifts electrons to a lower redox potential suitable for proton reduction, at the expense of energy derived from ATP hydrolysis.

Experimental evidence of such a reversed electron transport has been provided recently in our laboratory (128). In butyrate-grown cells of $S$. wolfei, high activities of membranebound ATPase were detected. 3-Hydroxybutyryl-CoA dehydrogenase was found exclusively in the cytoplasmic cell fraction, whereas butyryl-CoA dehydrogenase and hydrogenase were to significant extents $(>15 \%)$ membrane associated. Unfortunately, these enzymes did not bind firmly to the membrane and could not be reconstituted there either, thus preventing further study of this energy-coupling system in membrane vesicles. Hydrogen production from butyrate was therefore studied in intact cell suspensions of $S$. wolfei in the presence of bromoethane sulfonate to inhibit methanogenic hydrogen oxidation. $S$. wolfei accumulated hydrogen to $60 \mathrm{~Pa}$, with concomitant acetate production. This accumulation could be prevented by the addition of the protonophore CCCP (carbonyl cyanide $p$-chlorophenylhydrazone) or the ATPase inhibitor DCCD $\left(N, N^{\prime}\right.$-dicyclohexyl carbodiimide), indicating that a membrane-bound, ATP-dependent step was involved in butyrate degradation. In control experiments with crotonate as the substrate, neither compound had any effect on hydrogen formation, thus proving that the critical, sensitive step was the oxidation of the butyryl to the crotonyl residue.

Hydrogen and acetate accumulated in these experiments to a concentration which corresponded to a residual free energy

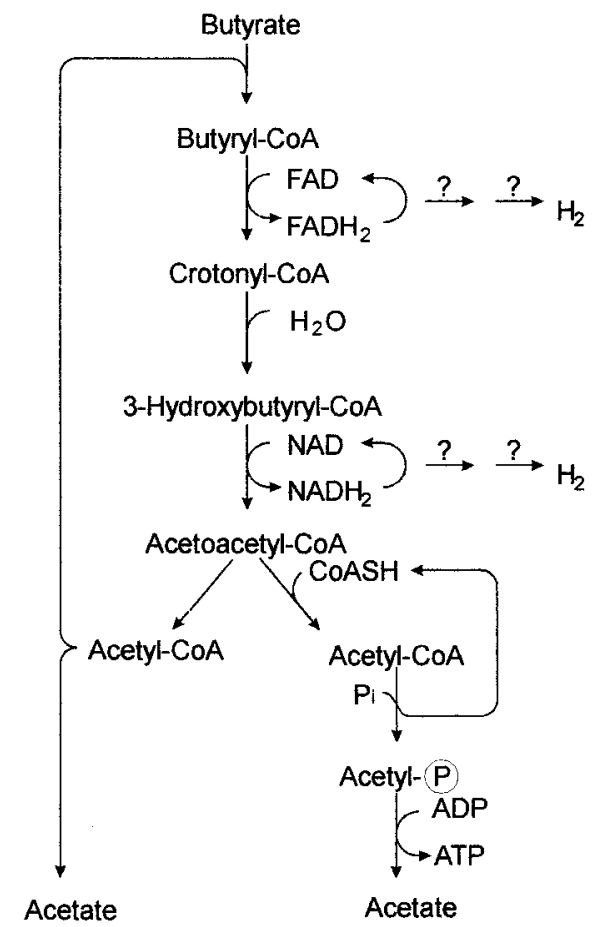

FIG. 4. Pathway of butyrate degradation by Syntrophomonas wolfei. One ATP molecule is formed by substrate-level phosphorylation. 


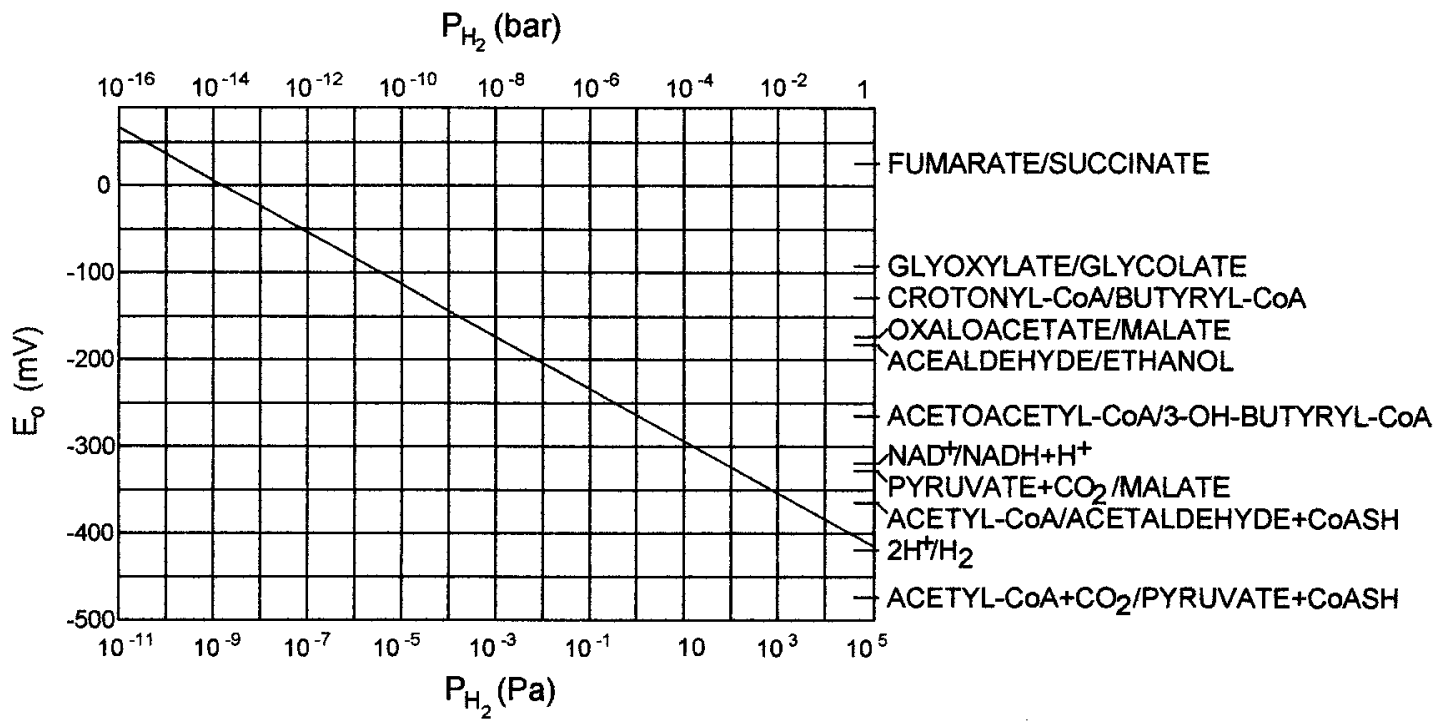

FIG. 5. Graph of the dependence of the redox potential on the prevailing hydrogen partial pressure at $\mathrm{pH}$ 7.0. On the right, standard potentials of redox reactions relevant to syntrophic oxidation processes are added for comparison. Modified from references 95 and 97.

of $-23 \mathrm{~kJ}$ for the butyrate oxidation reaction, about the amount of energy defined above as the minimum amount necessary to sustain energy metabolism by these bacteria. Obviously, they do not burn down their "battery" to zero before they stop but leave a minimum tension from which they can resume work as soon as hydrogen is removed again.

There is no information yet on how the components of such a reversed electron transport system are arranged in these bacteria. Copper chloride has been used repeatedly as an inhibitor of hydrogenases to obtain information about their orientation in the cytoplasmic membrane $(4,25)$. The hydrogenase activity of intact cell suspensions of $S$. wolfei could be inhibited to a large extent by copper chloride (35), indicating that the active site of this enzyme faces the periplasmic space. A menaquinone and also traces of a $c$-type cytochrome were found in $S$. wolfei cells; however, the cytochrome was found to a greater extent in non-syntrophically grown cells (76). Other syntrophic butyrate oxidizers such as Syntrophospora bryantii do not contain cytochromes at all (35); obviously, cytochromes are not necessarily essential carriers in syntrophic butyrate oxidation. It appears evident that butyryl-CoA dehydrogenase operates on the cytoplasmic surface of the cell membrane. Depending on whether the active site of the hydrogenase enzyme faces the cytoplasmic or the periplasmic space of the cells, the quinone has to act in this electron transport chain as an active proton transducer (Fig. 6A) or not (Fig. 6B). In the latter case, a very simple system for reversed electron transport driven by the proton gradient, which does not need to involve electron carriers between the dehydrogenase and the hydrogenase proteins, can be proposed.

If two protons are transferred in this hypothesized reversed electron transport system, one-third of the ATP synthesized by substrate-level phosphorylation would remain for growth and maintenance of the fatty acid-oxidizing bacterium, in accordance with the above assumptions.

The energetic situation of a binary mixed culture degrading butyrate to acetate and methane is considerably more difficult:

$$
\begin{gathered}
2 \mathrm{CH}_{3} \mathrm{CH}_{2} \mathrm{CH}_{2} \mathrm{COO}^{-}+\mathrm{CO}_{2}+2 \mathrm{H}_{2} \mathrm{O} \rightarrow 4 \mathrm{CH}_{3} \mathrm{COO}^{-}+ \\
2 \mathrm{H}^{+}+\mathrm{CH}_{4}\left(\Delta G^{\circ \prime}=-35 \mathrm{~kJ} \text { per } 2 \text { mol of butyrate }\right)
\end{gathered}
$$

This overall reaction has to feed two organisms in three partial reactions; each step has only $12 \mathrm{~kJ}$ available under standard conditions, and this changes to $-58 \mathrm{~kJ}$ at butyrate and acetate concentrations in the range of $10 \mathrm{mM}$, as used in laboratory cultures. Under these conditions, the energetic situation of the butyrate oxidizer is difficult, especially near the end of the substrate conversion process. One could speculate that ATP formation is more efficient in these cells than in others and that less energy is lost as heat, but this idea is hardly convincing. Probably the energy of the cells under these (artificial) growth conditions is suboptimal, and ATP synthesis requires less ATP than is necessary in the cell at full energy charge, as we as-
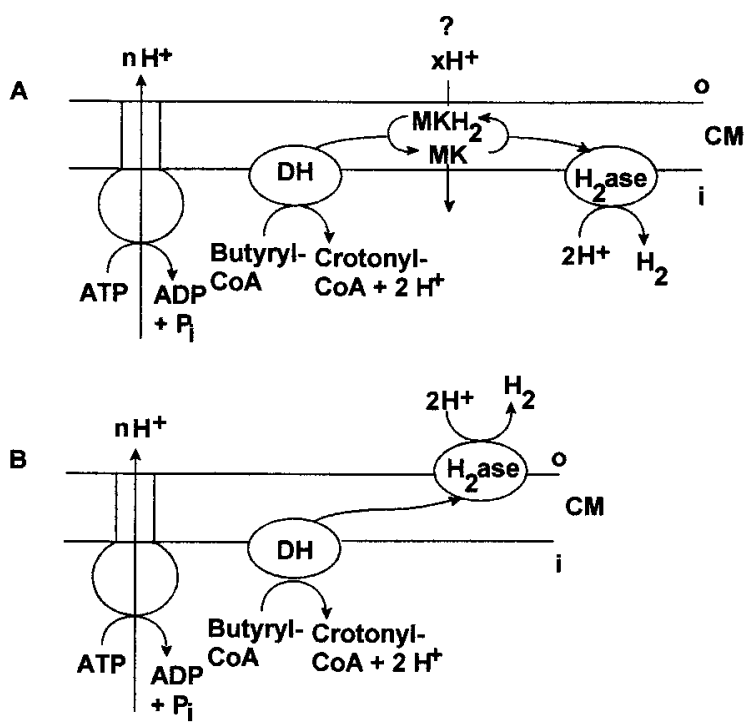

FIG. 6. Hypothetical scheme of organization of enzymes and redox carriers in the cytoplasmic membrane of the butyrate-degrading bacterium Syntrophomonas wolfei. $\mathrm{i}$, inside; $\mathrm{o}$, outside; $\mathrm{DH}$, dehydrogenase; $\mathrm{H}_{2}$ ase, hydrogenase; $\mathrm{MK}$, menaquinone. (A and B) Two different concepts for the scheme (see the text). Redrawn from reference 97. 


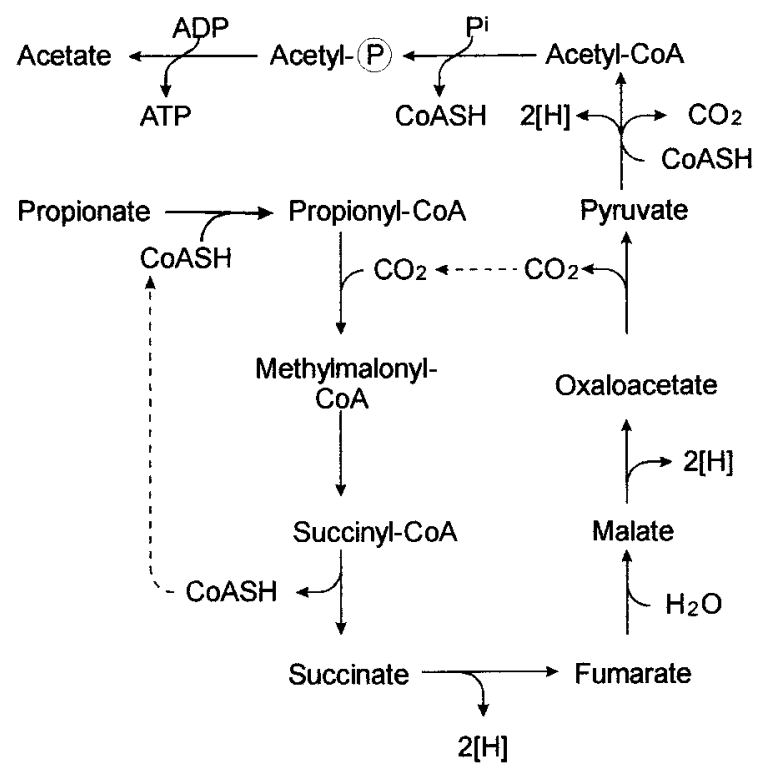

FIG. 7. Pathway of propionate oxidation by syntrophically fermenting bacteria. One ATP molecule is synthesized by substrate-level phosphorylation.

sumed above. Very slow, often nonexponential growth and substrate turnover, as are usually observed with such binary mixed cultures (37), indicate that the energy supply is insufficient. We have often observed, as did other authors, that accumulating acetate $(>20 \mathrm{mM})$ substantially inhibits butyrate degradation in such cultures.

The energetic difference between the ternary mixed culture described above and an artificial binary mixed culture demonstrates that the acetate-cleaving methanogens have a very important function in removal of acetate and, with this, "pull" the butyrate oxidation reaction. This view is especially intriguing because acetate cleavage to methane and $\mathrm{CO}_{2}$ was for a long time doubted to be able to supply energy for growth to the methanogenic bacteria themselves (146). The above calculations also explain why addition of an acetate-cleaving methanogen to a defined binary mixed culture enhances growth and substrate turnover considerably $(2,8)$.

Syntrophic oxidation of long-chain fatty acids from lipid hydrolysis probably involves $\beta$-oxidation with concomitant release of electrons as hydrogen via reversed electron transport, analogous to the process described above for butyrate oxidation. Long-chain dicarboxylic acids are degraded stepwise by $\beta$-oxidation, analogous to fatty acids, and decarboxylation occurs at the $\mathrm{C}_{5}$ or $\mathrm{C}_{4}$ state (glutarate or succinate) (73).

\section{ENERGETICS AND BIOCHEMISTRY OF PROPIONATE OXIDATION} tion

For syntrophic propionate oxidation, according to the equa-

$$
\begin{gathered}
4 \mathrm{CH}_{3} \mathrm{CH}_{2} \mathrm{COO}^{-}+4 \mathrm{H}^{+}+2 \mathrm{H}_{2} \mathrm{O} \rightarrow 7 \mathrm{CH}_{4}+5 \mathrm{CO}_{2} \\
\left(\Delta G^{\circ \prime}=-249 \mathrm{~kJ} \text { per } 4 \mathrm{~mol} \text { of propionate }\right)
\end{gathered}
$$

a scheme similar to that in Fig. 3 can be drawn, again leaving a free energy change in the range of -22 to $-23 \mathrm{~kJ}$ per mol (11 partial reactions) for all partners involved, including the syntrophic propionate oxidizer $(95,112)$. The pathway of propionate oxidation in such bacteria is basically a reversal of classical fermentative propionate formation, with methyl-
malonyl-CoA, succinate, malate, pyruvate, and acetyl-CoA as intermediates $(57,58,61,93,95)$ (Fig. 7). The initial substrate activation is accomplished by CoA transfer from acetyl-CoA $(58,87)$ or succinyl-CoA, with one ATP molecule being formed in a substrate-level phosphorylation step (succinate thiokinase or acetate kinase). Of the redox reactions involved, succinate oxidation and malate oxidation are the most difficult to couple to proton reduction (Table 1; Fig. 5); hydrogen partial pressures of $10^{-3}$ or $10^{-10} \mathrm{~Pa}$ would be required, respectively; these are again far lower concentrations than a methanogen can maintain (see above). The enzymes and electron transfer components involved in propionate oxidation were studied with Syntrophobacter wolinii $(58,87)$ and Syntrophobacter pfennigii (130). Studies of this kind became much easier after binary mixed cultures with only one methanogenic bacterium and even pure cultures of syntrophic propionate oxidizers became available (129). Of the enzymes involved, at least the succinate dehydrogenase activity appeared to be firmly bound to the membrane, as did ATPase and part of the hydrogenase activity (35). In experiments with suspensions of intact cells similar to those described above for butyrate oxidation, hydrogen was formed from propionate to an equilibrium concentration of about $40 \mathrm{~Pa}$ and was strictly inhibited by addition of CCCP or DCCD (Fig. 8). This indicates again that an intact (proton?) motive force maintained by ATP hydrolysis is required for hydrogen release, probably in the first oxidation step. Unfortunately, no suitable control experiment could be run to prove this assumption: for propionate, there is no simple oxidized analog as crotonate was in the butyrate system mentioned above; fumarate and malate are not suitable either, because their transport into the cell may imply electrogenic side effects. Menaquinone and cytochromes $b$ and $c$ were detected in these bacteria (35). Their respective localization, orientation, and physiological role in the electron transport system still need to be elucidated. A tentative reaction scheme for a "reversed electron transport" system for propionate oxidation could be based on a reversal of hydrogen-dependent fumarate reduction by Wolinella succinogenes (63); however, a reliable concept of electron transport organization in the cytoplasmic membrane can be proposed only when more data on this system have been obtained. Recent studies in the laboratory of A. Stams in Wageningen have provided evidence that

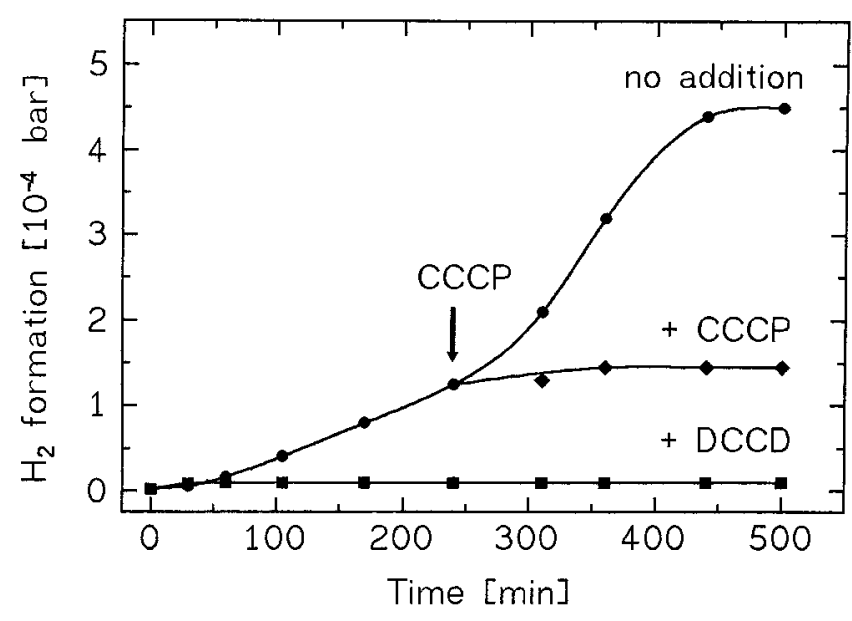

FIG. 8. Hydrogen formation from $20 \mathrm{mM}$ propionate by dense cell suspensions of Syntrophobacter wolinii. $\bullet$, no further additions; $\mathbf{\square}$, after preincubation with DCCD ( $25 \mathrm{nmol}$ per $\mathrm{mg}$ of protein) for $25 \mathrm{~min}$; , after addition of CCCP (10 nmol per $\mathrm{mg}$ of protein) at $240 \mathrm{~min}$. Reprinted from reference 35 with permission. 
not only hydrogen but also formate could contribute to interspecies electron transport in this system: syntrophic propionate oxidation with their strain MPOB was possible only in cooperation with formate- and hydrogen-oxidizing methanogens, not with Methanobrevibacter strains that are only able to oxidize hydrogen (33). The subject will be discussed below.

The situation is complicated further by the fact that all syntrophic propionate-oxidizing bacteria known so far have turned out to be able to reduce sulfate also $(49,50,129,130)$. Thus, electron transport components detected in these bacteria even after growth in syntrophic mixed culture are not necessarily involved in syntrophic oxidation but, rather, may be involved in the sulfate reducing apparatus.

An early report suggested that syntrophic propionate oxidation could also proceed through a different pathway (122). Experiments with position-labelled propionate indicated that in an experiment with sewage sludge the labelling pattern of the acetate formed did not agree with a randomizing pathway such as the methylmalonyl-CoA pathway. One could speculate that these bacteria oxidize propionate through a reversal of the acrylyl-CoA pathway of propionate formation. Unfortunately, the bacteria involved could never be isolated, and studies on the biochemistry or energetics of this pathway are lacking.

\section{ENERGETICS AND BIOCHEMISTRY OF GLYCOLATE OXIDATION}

Glycolate is oxidized syntrophically by homoacetogenic and methanogenic cocultures to $2 \mathrm{CO}_{2}$, and hydrogen is the electron carrier between the fermenting bacterium (later called Syntrophobotulus glycolicus) and a hydrogen-oxidizing partner bacterium $(45,46)$. The primary fermentation is an endergonic process under standard conditions (Table 1) and requires coupling to, e.g., a methanogenic bacterium. The degradation pathway includes the oxidation of glycolate to glyoxylate, condensation of glyoxylate with acetyl-CoA to form malyl-CoA, ATP formation in a malyl-CoA synthetase reaction, malate oxidation and decarboxylation by the malic enzyme, and oxidative decarboxylation of pyruvate to acetyl-CoA through pyruvate synthase, thus closing the chain for a new reaction cycle (45) (Fig. 9). Three redox reactions are involved in this oxidation; they are catalyzed, separately, by glycolate dehydrogenase, malic enzyme, and pyruvate ferredoxin oxidoreductase. Proton reduction with these electrons poses a major problem only with the first reaction (Table 1; Fig. 5): direct proton reduction would require a hydrogen partial pressure at $10^{-6}$ $\mathrm{Pa}$, which cannot be maintained by homoacetogenic or methanogenic bacteria. Again, a reversed electron transport system has to be postulated, which has to be fueled by partial hydrolysis of the ATP formed in substrate-level phosphorylation.

Indirect evidence of such a reversed electron transport has been obtained from hydrogen accumulation experiments similar to those reported above for butyrate and propionate oxidation: hydrogen production from glycolate by intact cells was inhibited by CCCP (42a). With carefully prepared membrane vesicle suspensions, a methylene blue-reducing glycolate dehydrogenase, as well as ATPase and hydrogenase, was found to be membrane bound to a significant extent (25 to 97\%). Direct proof of proton gradient-dependent hydrogen release was provided in experiments with membrane vesicles prepared from the glycolate-fermenting bacterium: such vesicles converted glycolate stoichiometrically to glyoxylate and hydrogen in the presence of ATP. This hydrogen formation was abolished entirely by the addition of $\mathrm{CCCP}$ and other protonophores, as well as by DCCD. Monensin and other sodium ionophores had no specific effect (43). The process is even reversible: mem-

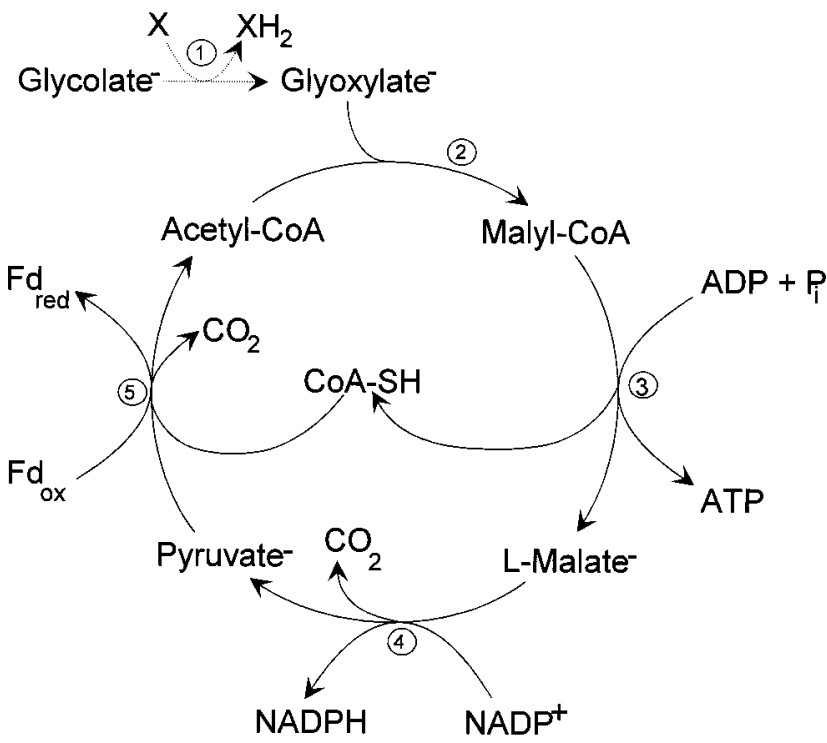

FIG. 9. Pathway of glycolate oxidation by Syntrophobotulus glycolicus. One ATP molecule is synthesized by substrate-level phosphorylation. X represents an unknown electron carrier, perhaps menaquinone.

brane vesicles incubated in the presence of glyoxylate and hydrogen catalyzed a substrate-dependent net synthesis of ATP from ADP and inorganic phosphate $\left(\mathrm{P}_{\mathrm{i}}\right)$, and the rate of ATP synthesis was in the range of 20 to $50 \%$ of that for glyoxylate reduction (44). This "glyoxylate respiration" represents the reversal of the postulated proton potential-dependent reversed electron transport.

So far, we do not know which electron carriers are involved in this transport system and how the enzymes involved are organized in the membrane. The bacterium contains menaquinone $\mathrm{K}_{9}$ and traces of menaquinones $\mathrm{K}_{8}$ and $\mathrm{K}_{10}$ but no cytochromes. Inhibition experiments with intact cell suspensions revealed that the glycolate dehydrogenase and methylene bluereducing hydrogenase activities of the glycolate-fermenting bacterium were specifically inhibited by $\mathrm{CuCl}_{2}$, indicating that a copper-sensitive part of both enzymes is accessible from the periplasmic space (Fig. 10B). Depending on the orientation of these enzymes and on whether the menaquinone acts as an active proton transporter in the membrane or not, different options of functional organization of the various electron carriers in the membrane can be suggested (Fig. 10). Efforts in our laboratory to purify the enzyme components of this system have met with only limited success so far, and reconstitution experiments have not yet been carried out.

Glycolate-dependent hydrogen accumulation by membrane vesicles reached an equilibrium value at $3.9 \times 10^{2} \mathrm{~Pa}$ of $\mathrm{H}_{2}$ (42a). This value, together with the respective glycolate (6.7 $\mathrm{mM})$ and glyoxylate $(2.3 \mathrm{mM})$ concentrations, corresponds to an energy expenditure in this step of $+46 \mathrm{~kJ}$ per mol of glycolate, indicating that about two-thirds of an ATP unit has to be spent to reach the observed steady-state conditions. The ratio between hydrogen-dependent glyoxylate reduction and ATP formation in isolated membrane vesicle preparations $(0.2$ to $0.5 \mathrm{~mol}$ per mol) (44) also indicates that probably two-thirds of an ATP unit can be formed this way per reaction. Thus, at least with this system, we have rather reliable data on the reaction stoichiometry. 

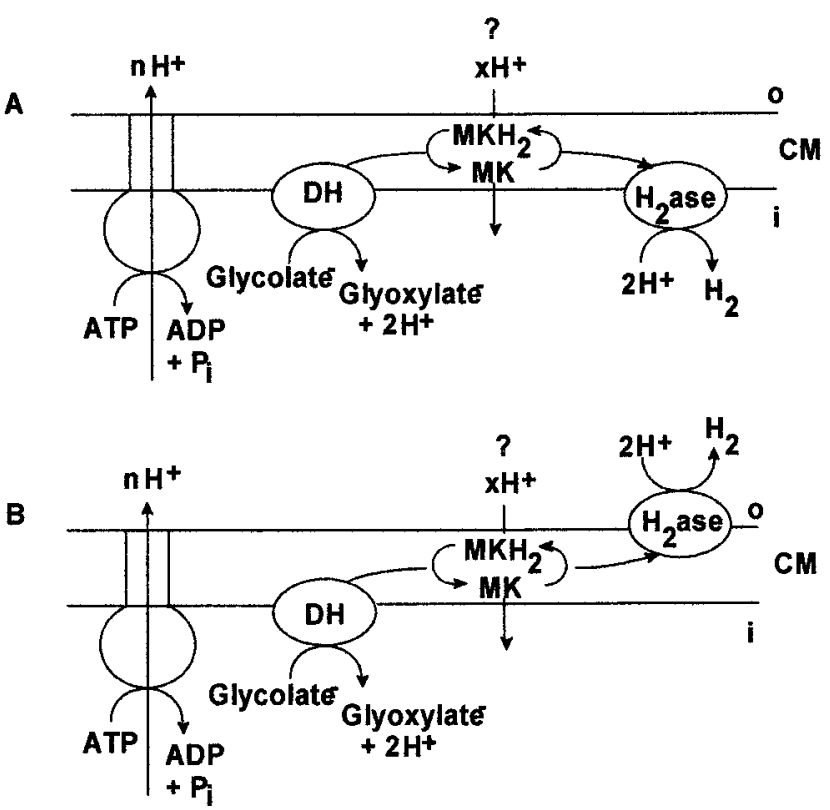

FIG. 10. Hypothetical scheme of the organization of enzymes and redox carriers in the cytoplasmic membrane of the glycolate-degrading Syntrophobotulus glycolicus. i, inside; o, outside; $\mathrm{CM}$, cytoplasmic membrane; $\mathrm{DH}$, dehydrogenase; $\mathrm{H}_{2}$ ase, hydrogenase; $\mathrm{MK}$, menaquinone. (A and $\mathrm{B}$ ) Two different concepts for the scheme (see the text).

\section{ENERGETICS AND BIOCHEMISTRY OF ETHANOL OXIDATION}

Although methanogenic ethanol degradation was actually the first case of syntrophic interspecies hydrogen transfer studied, the energetics of this system are far from clear. The total fermentation

$$
2 \mathrm{CH}_{3} \mathrm{CH}_{2} \mathrm{OH}+\mathrm{CO}_{2} \rightarrow 2 \mathrm{CH}_{3} \mathrm{COO}^{-}+2 \mathrm{H}^{+}+\mathrm{CH}_{4}
$$

yields $-112 \mathrm{~kJ}$ per $2 \mathrm{~mol}$ of ethanol under standard conditions. On the side of the ethanol oxidizer, e.g., "Methanobacillus omelianskii" S (18) or other fermenting anaerobes with similar metabolic capacities such as Pelobacter acetylenicus (92), ethanol dehydrogenase, acetaldehyde ferredoxin oxidoreductase (acetyl-CoA forming), phosphotransacetylase, and acetate kinase are involved, forming one ATP molecule per ethanol through substrate-level phosphorylation. Since the methanogenic hydrogen oxidizer requires at least one-third of an ATP unit for growth $(-20 \mathrm{~kJ}$ per reaction [see above]), only about $-45 \mathrm{~kJ}$ is available to the ethanol oxidizer per mol of ethanol oxidized, which is too little energy to form one full ATP molecule. It has to be postulated again, therefore, that part of the energy bound in ATP has to be reinvested somewhere to "push" the overall reaction and balance the energy budget.

Energetically, the most difficult reaction in ethanol oxidation is the ethanol dehydrogenase reaction (Table 1; Fig. 5). Recent experiments in our laboratory with Pelobacter acetylenicus have demonstrated that these bacteria contain a conventional, NAD-dependent alcohol dehydrogenase enzyme; also, acetaldehyde oxidation to acetyl-CoA with benzyl viologen as the electron acceptor proceeds in the cytoplasm without any unusual energetic implications (52). However, the formation of molecular hydrogen from NADH is catalyzed only in the presence of membrane vesicles, requires ATP, and is entirely abolished by protonophores (52). These results indicate that part of the ATP gained by substrate-level phosphorylation is reinvested into a proton-driven reversed electron transport system. Unfortunately, we have no information on the stoichiometry of coupling between ATP hydrolysis and electron transport. Cell yields determined with $P$. acetylenicus in coculture with various hydrogen scavengers were low (1.7 to $2.2 \mathrm{~g}$ per mol [107]), indicating that probably only one-third of an ATP unit per reaction was available for growth of these bacteria and twothirds was invested into the postulated reversed electron transport. This would mean that the syntrophic ethanol oxidizers keep only one-third of an ATP unit per reaction and the methanogenic partner does the same, so that the overall energy span of $-112 \mathrm{~kJ}$ per two ethanol molecules oxidized would be transformed to only three-thirds of an ATP unit, one-third for every partial reaction. At first sight, this looks like a waste of energy, but it would give the total system more freedom in energy exploitation: the hydrogen concentrations could fluctuate in a much broader range than in syntrophic fatty acid oxidation. Indications of such freedom were obtained in continuous ethanol-fermenting syntrophic cultures $(106,107)$.

Similar problems to those in ethanol oxidation must be expected to occur in syntrophic oxidation of primary amines. Unfortunately, we have had no chance to study such cultures into any biochemical detail in our laboratory.

\section{OXIDATION OF AROMATIC COMPOUNDS}

So far, defined syntrophic cocultures for methanogenic degradation of aromatic substrates exist only for benzoate, gentisate, and hydroquinone (Table 2). The biochemistry of anaerobic degradation of aromatic compounds has been studied in most detail so far with benzoate, and a degradation pathway has been elaborated in the last few years mainly with phototrophic and nitrate-reducing bacteria (see references 40, 47, and 100 for reviews). The basic concept is an initial activation to benzoyl-CoA by an acyl-CoA synthetase reaction requiring two ATP equivalents, followed by partial ring saturation and subsequent ring opening by a mechanism analogous to $\beta$-oxidation of fatty acids (Fig. 11). The resulting $\mathrm{C}$ dicarboxylic acid undergoes further $\beta$-oxidation to form three acetate residues and one $\mathrm{CO}_{2}$ molecule. The postulate found in earlier publications that succinate and odd-numbered fatty acids are formed as degradation intermediates could never be confirmed in defined cultures. Possibly, these compounds were formed as side products of secondary reactions occurring in undefined enrichment cultures and in the presence of degradation inhibitors.

The key reaction of this pathway, the reductive dearomatization of benzoyl-CoA, leads in nitrate reducers to cyclohexadi-2,6-ene carboxyl-CoA, which undergoes further hydration, probably to 2,6-dihydroxycyclohexane carboxyl-CoA (60). The initial reduction reaction by these bacteria with two electrons is coupled to hydrolysis of two ATP units (46a), making the total process rather ATP consuming (four ATP units consumed before ring cleavage). Nitrate reducers will easily gain these ATP investments back during subsequent oxidation of the acetyl residues. Fermenting bacteria excrete the acetate and can gain only three ATP units back during thiolytic cleavage of the pimelyl-CoA residue and the phosphotransacetylase and acetate kinase reactions involved. There may be a further gain of one-third of an ATP unit in decarboxylation of glutaconyl CoA (analogous to Acidaminococcus fermentans [20]), but hydrogen release from glutaryl-CoA oxidation by glutaryl-CoA dehydrogenase $\left(\mathrm{E}_{0}{ }^{\prime} \approx-120 \mathrm{mV}\right)$ will probably need an energy investment in reversed electron transport, analogous to butyryl-CoA oxidation (see above). Obviously, fermenting bacteria which convert benzoate to three acetate, one $\mathrm{CO}_{2}$, and three 

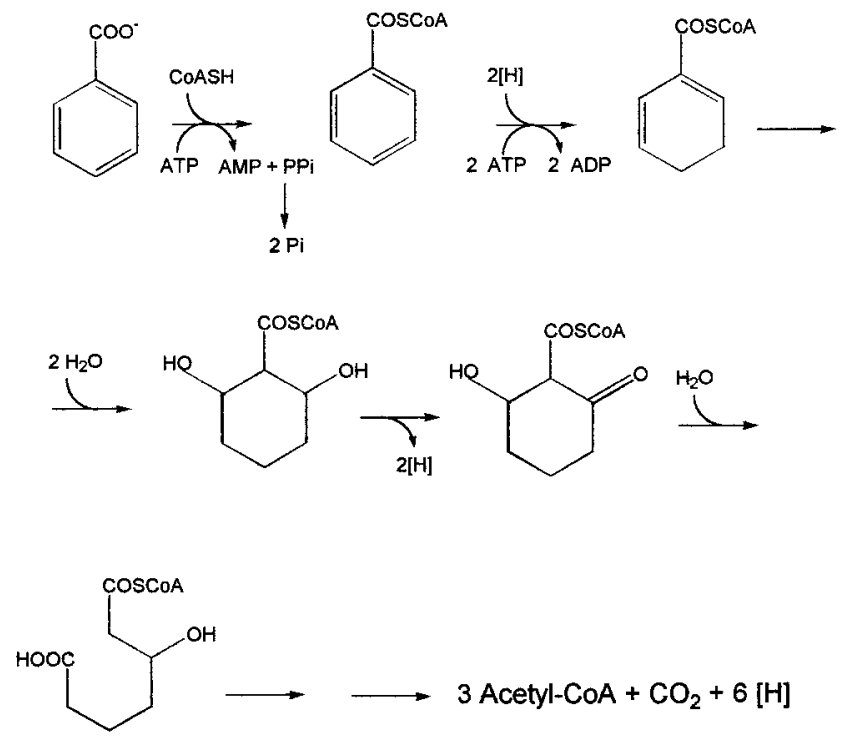

FIG. 11. Initial steps in anaerobic benzoate degradation on the basis of evidence obtained with the nitrate-reducing bacterium Thauera aromatica. Further metabolism of the acetyl residues formed differs with the metabolic groups of bacteria considered.

hydrogen molecules cannot expend so much ATP in benzoate activation or in the reduction of benzoyl-CoA. Either these reactions are accomplished with less ATP expenditure, e.g., by an acetyl-CoA:benzoate-CoA transferase reaction, or the reductive step has to run with no or less ATP investment. Studies on a syntrophically benzoate-degrading isolate indicated that benzoate is activated by a benzoate-CoA ligase in these bacteria (3). Further enzyme studies on benzoate degradation by syntrophic fermenting bacteria are lacking so far. Unfortunately, this makes the assessment of the energetic situation of these bacteria quite difficult.

Methanogenic benzoate degradation in binary and ternary mixed cultures proceeds according to the following equations:

$$
\begin{aligned}
& 4 \mathrm{C}_{6} \mathrm{H}_{5} \mathrm{COO}^{-}+18 \mathrm{H}_{2} \mathrm{O} \rightarrow 12 \mathrm{CH}_{3} \mathrm{COO}^{-}+8 \mathrm{H}^{+}+3 \mathrm{CH}_{4}+\mathrm{CO}_{2} \\
& \left(\Delta G^{\circ \prime}=-194 \mathrm{~kJ} \text { per } 4 \mathrm{~mol} \text { of benzoate, or }-28 \mathrm{~kJ}\right. \text { per } \\
& \text { partial reaction [seven reactions]) } \\
& \begin{array}{c}
\left(\Delta G^{\circ \prime}=-4 \mathrm{C}_{6} \mathrm{H}_{5} \mathrm{COO}^{-}+4 \mathrm{H}^{+} \rightarrow 15 \mathrm{CH}_{4}+13 \mathrm{CO}_{2}\right. \\
\text { partial reaction [19 reactions] })
\end{array}
\end{aligned}
$$

Obviously, the free energy change per substrate molecule and per partial reaction is significantly larger than in fatty acid degradation. One could speculate that acetate removal should have no significant influence on the energetics of benzoate degradation because the minimum energy quantum of $-20 \mathrm{~kJ}$ is easily secured in both the presence and absence of acetate consumers.

Recent experiments in our laboratory with Syntrophus gentianae (130) do not support this assumption (104). Benzoate was nearly completely converted to acetate, methane, and $\mathrm{CO}_{2}$ in binary mixed cultures with Methanospirillum hungatei as the hydrogen scavenger. Remnant benzoate concentrations at apparent equilibrium (in the range of 20 to $70 \mu \mathrm{M}$ ) increased in the presence of added acetate or propionate and decreased in the presence of a more efficient hydrogen consumer, e.g., a sulfate-reducing partner. The corresponding hydrogen concentrations measured in such cultures were in the range of 0.5 to $5 \mathrm{~Pa}$, leaving a total $\Delta G$ of -30 to $-45 \mathrm{~kJ}$ per mol for the benzoate degrader. Similar results were obtained during studies on the kinetics of benzoate degradation with a new syntrophic isolate in the presence of a sulfate-reducing partner bacterium (132): accumulating acetate in the culture medium inhibited benzoate degradation in an uncompetitive manner, and the measurable threshold concentrations of benzoate utilization decreased in the presence of nitrate as an alternative electron acceptor. Again, the residual free energy in the system at apparent reaction equilibrium was in the range of -30 to $-42 \mathrm{~kJ}$ per mol. This amount is equivalent to about two-thirds of an ATP unit, indicating that these bacteria depend on a higher "minimum-energy" basis than assumed above, perhaps two-thirds of an ATP unit per reaction. So far, we have no experimentally based explanation for this observation.

The dearomatizing reduction of benzoyl-CoA by syntrophically fermenting bacteria does not necessarily involve the same primary product as with the nitrate-reducing bacteria discussed above. Early reports on the formation of cyclohexane carboxylate in benzoate-degrading methanogenic enrichment cultures may indicate that fermenting (and perhaps also sulfatereducing) bacteria could reduce the aromatic ring further, perhaps to a cyclohexene or cyclohexane derivative, thus possibly overcoming the above-mentioned high ATP investments in dearomatization because these reductions then become less endergonic. However, $\beta$-oxidative cleavage and degradation of a saturated ring derivative by syntrophically fermenting bacteria would require energy expenditure in reversed electron transport steps, analogous to butyrate oxidation. At the very end, the overall energy gain cannot exceed one- to two-thirds of an ATP unit per reaction. In any case, we need reliable information on the dearomatization reactions and their energetic implications before we can draw a clearer picture of the overall energetics of these bacteria.

Fermentation of hydroxylated benzoates releases more energy than does fermentation of benzoate itself, and with at least two hydroxy groups on the ring, fermentation by pure cultures is basically possible, making syntrophic coupling unnecessary. Phenol is first carboxylated to a 4-hydroxybenzoate derivative and enters the benzoate pathway as such $(47,101)$. The carboxylation is an endergonic reaction consuming one ATP equivalent in nitrate-reducing bacteria (64). Whether fermenting phenol degraders spend the same amount of energy in this step remains to be elucidated. Therefore, a detailed analysis of the energetic situation of syntrophic fermentative phenol degradation is not yet possible.

\section{ACETATE OXIDATION}

Syntrophic oxidation of acetate had been suggested in 1936 by Barker (5) as a general concept for acetate fermentation to methane and $\mathrm{CO}_{2}$, but it was observed experimentally only recently, first with bacteria isolated from a slightly thermophilic digestor $\left(58^{\circ} \mathrm{C}\right)(149)$. The syntrophic acetate oxidizer could be grown in pure culture, and it turned out to be a homoacetogenic bacterium (66) which can also grow and run its energy metabolism by hydrogen-dependent reduction of $\mathrm{CO}_{2}$ to acetate, thus reversing syntrophic acetate oxidation. Biochemical studies revealed that it uses the carbon monoxide dehydrogenase pathway (Wood pathway) as do other homoacetogens (67). Two properties make this bacterium (strain AOR) extremely interesting. The first is that the small energy span of acetate conversion to methane and $\mathrm{CO}_{2}$, which was for a long time believed to be incapable of supporting the energy metabolism of one bacterium (146), now appears to be sufficient to feed even two bacteria: 


$$
\begin{gathered}
\mathrm{CH}_{3} \mathrm{COO}^{-}+\mathrm{H}^{+} \rightarrow \mathrm{CH}_{4}+\mathrm{CO}_{2} \\
\left(\Delta G^{\circ \prime}=-36 \mathrm{~kJ} \text { per mol, or }-18 \mathrm{~kJ} \text { per partial reaction }\right)
\end{gathered}
$$

This calculation shows that the partial reactions end up in the same range of free energy changes which were calculated above for other fatty acid oxidations as well, although at its lower limit. Actually, the free energy change is slightly higher at $58^{\circ} \mathrm{C}(-42 \mathrm{~kJ}$ per mol [Fig. 11]) than under standard conditions $\left(25^{\circ} \mathrm{C}\right)$. Recently, however, two syntrophic acetate-oxidizing cultures which operate at 30 or $35^{\circ} \mathrm{C}$ have been described (90, 102, 103), proving that the above-mentioned energy changes are sufficient for acetate degradation and (very little) growth at these temperatures as well. The second interesting feature of strain AOR is that it can perform acetate formation and acetate degradation, in both directions, with probably the same biochemical reaction apparatus, simply depending on the prevailing concentrations of substrates and products, and can even synthesize ATP in both directions. The fact that simply a change of substrate and product concentrations can shift a total metabolic system into its opposite direction illustrates how close to the thermodynamic equilibrium the energy metabolism of an anaerobic bacterium can operate; it will hardly be possible to grow an aerobic heterotroph on $\mathrm{CO}_{2}$ and $\mathrm{H}_{2} \mathrm{O}$, no matter how high their concentrations and how low those of oxygen and glucose!

It is worth spending a few sentences here on the temperature dependence of these transformation reactions. Figure 12 shows that according to the van't Hoff equation,

$$
\Delta \mathrm{G}=\Delta \mathrm{H}-\mathrm{T} \Delta \mathrm{S}
$$

the free energy change of acetate conversion to methane and $\mathrm{CO}_{2}$ increases slightly with increasing temperature. This may explain why at temperatures of $35^{\circ} \mathrm{C}$ and lower, this reaction is typically carried out by one single bacterium, e.g., Methanosarcina barkeri or Methanosaeta soehngenii, and that syntrophic associations of the above-mentioned type operate nearly exclusively at elevated temperatures. Nonetheless, acetate conversion to methane at higher temperatures can also be performed by one single aceticlastic methanogen, e.g., Methanosarcina thermophila. Syntrophic acetate oxidation at lower temperatures is found only if further stress factors such as high ammoium concentrations inhibit the aceticlastic methanogens (102).

Figure 12 also shows that the cooperation of the two partners in the thermophilic process becomes possible at a hydrogen partial pressure close to $10 \mathrm{~Pa}$, and such partial pressures (10 to $50 \mathrm{~Pa}$ ) were actually determined in such cultures (68). At lower temperatures, this syntrophic cooperation requires substantially lower hydrogen partial pressures to provide the required energy for both partners.

Biochemical studies on one of the newly isolated mesophilic strains have proven again that they use the Wood pathway of acetate oxidation, similar to strain AOR (102a). However, we do not know yet to what extent and in which steps energy is being conserved by these bacteria, in either the acetate synthesis or acetate oxidation reaction chain. The hydrogen partial pressure measured in the syntrophic cultures is in the range of 10 to $50 \mathrm{~Pa}(68)$, corresponding to a redox potential of -200 $\mathrm{mV}$ (Fig. 5), which is identical to that of the methylenetetrahydrofolate reductase reaction (27). The other redox reactions in acetate oxidation have redox potentials at $-520,-300$, and $-430 \mathrm{mV}$ (27) and do not pose basic problems for hydrogen release under the observed conditions. However, we still do not know the steps at which energy is being conserved, and the actual redox potentials may change if they are coupled to, e.g., ion transfer reactions across the cytoplasmic membrane.

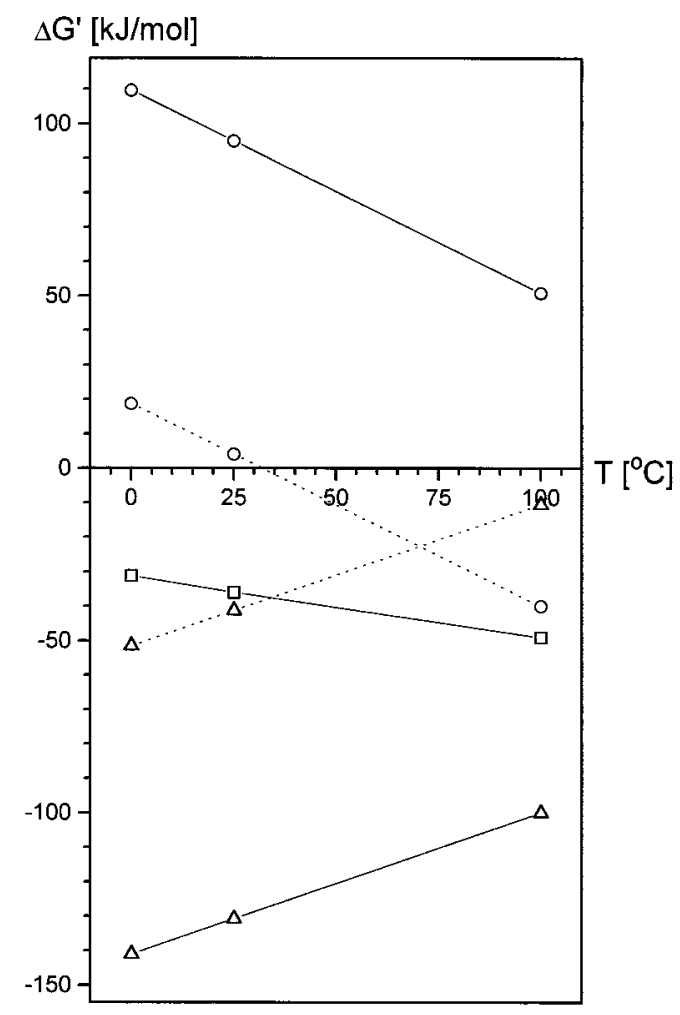

FIG. 12. Temperature dependence of the free energy change in anaerobic hydrogen and acetate metabolism, calculated from the van't Hoff equation with data from references 21,28 , and 65 . Solid lines, standard conditions (1 M concentrations, $10 \mathrm{~Pa}$ pressure); dashed lines, the same for $10 \mathrm{~Pa}$ of hydrogen. $\square$, $\mathrm{CH}_{3} \mathrm{COO}^{-}+\mathrm{H}^{+} \rightarrow \mathrm{CH}_{4}+\mathrm{CO}_{2} ; \mathrm{O}, \mathrm{CH}_{3} \mathrm{COO}^{-}+\mathrm{H}^{+}+2 \mathrm{H}_{2} \mathrm{O} \rightarrow 4 \mathrm{H}_{2}+$ $2 \mathrm{CO}_{2} ; \triangle, 4 \mathrm{H}_{2}+\mathrm{CO}_{2} \rightarrow \mathrm{CH}_{4}+2 \mathrm{H}_{2} \mathrm{O}$.

\section{OXIDATION OF BRANCHED-CHAIN FATTY ACIDS}

Branched-chain fatty acids are formed during fermentative degradation of the corresponding amino acids by oxidative deamination and decarboxylation (75). The further degradation does not pose any difficulties with 2-methylbutyrate (neovalerate) because it can be $\beta$-oxidized, analogous to butyrate, to acetate and propionate by, e.g., Syntrophospora bryantii (114).

Methanogenic degradation of isobutyrate proceeds via an isomerization to butyrate and further $\beta$-oxidation (116); the isobutyrate-butyrate isomerization has been described in a defined culture as a coenzyme $\mathrm{B}_{12}$-dependent rearrangement of the carbon skeleton (72). A similar isomerization may also occur as a side reaction with valerate, leading to the formation of 2-methylbutyrate (139).

Only one defined culture has been described so far as being capable of fermentative degradation of isovalerate (115). It is exclusively specialized for the degradation of this substrate and converts it, with $\mathrm{CO}_{2}$ as the cosubstrate, to three molecules of acetate and one molecule of hydrogen (Table 2). The pathway is rather complicated and involves a carboxylation, a dehydrogenation of a saturated fatty acid residue, and one substratelevel phosphorylation step (115). The whole conversion is endergonic under standard conditions and depends on syntrophic hydrogen removal. Since three acetate residues are released per substrate molecule oxidized, acetate should have a far more pronounced influence on the total energetics, but experimental evaluation of the influence of interspecies acetate versus interspecies hydrogen transfer has not yet been provided. 
Details of the energetics of this bacterium have been discussed previously (95).

\section{ANAEROBIC METHANE OXIDATION}

Anaerobic, sulfate-dependent methane oxidation appears to be an important redox reaction in anoxic marine sediments $(59,88)$, but so far nobody can explain which bacteria catalyze this reaction and how they overcome the problem of activation of the very stable methane molecule. Nobody so far has cultures at hand to study the biochemistry of this process; all efforts to isolate anaerobic methane oxidizers have failed so far, and all reports on putative methane-oxidizing anaerobes in the literature have turned out later to be unsubstantiated due to a lack of sufficient controls. Zehnder and Brock (143) have shown by radiotracer experiments that methanogenic bacteria themselves are also able to run the methane formation reaction backwards; however, in these assays, methane production always exceeded methane oxidation by two to three orders of magnitude. Therefore, these bacteria can hardly be responsible for a net methane oxidation, as postulated on the basis of methane distribution gradients in anoxic sediments and hypolimnic waters (reference 88 and literature therein).

From a thermodynamic point of view, sulfate-dependent methane oxidation is an exergonic reaction

$$
\mathrm{CH}_{4}+\mathrm{SO}_{4}{ }^{2-}+2 \mathrm{H}^{+} \rightarrow \mathrm{CO}_{2}+\mathrm{H}_{2} \mathrm{~S}+2 \mathrm{H}_{2} \mathrm{O}
$$

which yields a $\Delta G^{\circ \prime}$ of $-18 \mathrm{~kJ}$ per mol under standard conditions. The concentrations of the chemical reaction partners in situ at the active layers are in the range of $10^{3} \mathrm{~Pa}$ of methane and about 2 to $3 \mathrm{mM}$ each sulfate and free hydrogen sulfide. Thus, the overall energetics do not become significantly more favorable if the in situ conditions are taken into consideration. This amount of energy could feed only one single bacterium, provided that it is able to exploit this biological minimum energy quantum. The recent observations on the reversal of homoacetogenic fermentation by strain AOR and others (see above) make it tempting to speculate that "reversed methanogenesis" may be the key to this process, as suggested recently (54). If the overall reaction is actually a syntrophic cooperation involving a methanogen running methane formation backward and a sulfate-reducing bacterium, it is obvious that only one of the partners could gain metabolically useful energy from the reaction and that the other one had to run this process only as a cometabolic activity. This would explain at least why scientists have always failed to enrich for methane-oxidizing sulfate reducers in the past, simply because one cannot enrich for bacteria on the basis of cometabolic activities. Knowledge of the in situ concentration of the intermediate(s) transferred between both partners (hydrogen, acetate, methanol, formate?) would allow one to calculate which one of the two partners-if any bacterium at all-actually can conserve energy from this transformation. I believe that a new approach to this problem should be attempted, beginning with a search for suitable "reversible" methanogenic bacteria.

\section{INTERSPECIES FORMATE VERSUS HYDROGEN TRANSFER}

Although hydrogen appears to be an ideal electron carrier between bacteria of different metabolic types, due to its small size and easy diffusibility, formate could also act in a similar manner. A possible alternative involvement of formate in such electron transfer processes had been considered from the very beginning $(18,77)$ because the original partner bacteria could oxidize both hydrogen and formate. The standard redox potential of the $\mathrm{CO}_{2}$ /formate couple is nearly identical to that of $\mathrm{H}^{+} / \mathrm{H}_{2}$ ( -420 and $-414 \mathrm{mV}$, respectively), and hence the energetic problems are nearly the same with both. Since both electron carrier systems couple inside the cell with similar if not identical electron transfer components, e.g., ferredoxins, most bacteria involved in interspecies electron transfer exchange hydrogen with formate and vice versa (see, e.g., references 13 and 138). This renders a differentiation between both electron transfer systems rather difficult, and both carriers may even be used simultaneously (95). Therefore, a formate $/ \mathrm{CO}_{2}$ shuttle could replace hydrogen transfer, and this idea has been reviewed recently on the basis of experiments with undefined floc cultures from methanogenic fermentors (121) and pure cultures $(120,148)$, as well as on the basis of calculations of diffusion kinetics $(15,16,120)$.

Exclusive action of hydrogen as an electron carrier has been proven so far only with the butyrate-oxidizing coculture Syntrophomonas wolfei (134), the glycolate-oxidizing Syntrophobotulus glycolicus (43), and the thermophilic, syntrophically acetate-fermenting strain AOR $(66,68)$ : all these strains exhibit high hydrogenase and very little formate dehydrogenase activity in coculture. Syntrophic oxidation of propionate by strain MPOB or of butyrate by Syntrophospora bryantii requires partner bacteria that are able to use both hydrogen and formate, indicating that both carriers are active in interspecies electron transfer $(31-35,110)$. Nonetheless, hydrogenase activities in these cultures exceeded formate dehydrogenase activities substantially, indicating that hydrogen played a dominant role as electron carrier. Similar conclusions were drawn from hydrogen and formate transfer experiments with thermophilic granular sludge preparations and different partner bacteria (102). In isobutyrate-degrading cultures, formate appeared to play a role as an electron carrier as well as hydrogen (141). On the basis of calculations of diffusion kinetics (16), one can speculate that formate $/ \mathrm{CO}_{2}$ would be the preferred electron transfer system in suspended cultures of single cells where the carrier molecule has to diffuse a long distance through an aqueous phase, whereas hydrogen would be more efficient in densely packed aggregates which dominate in anaerobic digestors and probably also in sediments.

Energetically, there is no basic difference between the two carrier systems. Actually, the problem concerns reliable measurement of formate at low concentrations: at $0.3 \times 10^{5} \mathrm{~Pa}$ of $\mathrm{CO}_{2}$, which is typical of, e.g., sewage sludge and sediments, a hydrogen partial pressure of 0.1 to $1 \mathrm{~Pa}$, as required for the redox reactions discussed above (Fig. 5), is equivalent to formate concentrations of about 1 to $10 \mu \mathrm{M}$ (96). Whereas hydrogen partial pressures can be measured reliably today down to $10^{-2} \mathrm{~Pa}$ with mercuric oxide-based detectors, there is not an efficient method available which allows the measurement of formate at concentrations of a few micromolar units or less. Most indications of formate formation were obtained in the presence of inhibitors, etc., which accumulated measurable amounts of formate but may represent rather unphysiological situations.

The considerations mentioned in the foregoing sections demonstrate that at least the electron transfer systems discussed here can be modelled sufficiently on the basis of interspecies hydrogen transfer only. If we assume that both hydrogen and formate may be active in electron transfer simultaneously and that both couple with the same electron transfer components, the hydrogen partial pressures give a realistic picture of the redox situation in the system under consideration and, from this, its energetic situation. Nonetheless, one has to keep in 
mind that in some cases formate is also an important electron carrier for interspecies electron transfer.

\section{INTERSPECIES ACETATE TRANSFER}

Beyond hydrogen and formate, also acetate is excreted by syntrophically fermenting bacteria and is further metabolized by methanogens. The model introduced above shows that also acetate removal can have a profound influence on the total energetics of syntrophic degradation of fatty acids or benzoate. Its importance may be even higher with, e.g., isovalerate degradation, since three molecules of acetate and only one hydrogen molecule are formed (Table 1). Indeed, inhibition by acetate accumulations or additions has been reported for syntrophic degradation of fatty acids and for benzoate (2, 48, 126, 132).

A special situation is the fermentative conversion of acetone to methane and $\mathrm{CO}_{2}$ which is catalyzed by syntrophically cooperating bacteria as well. In this case, acetate is the only intermediate between both partners, as illustrated by the following equations:

$$
\begin{gathered}
\mathrm{CH}_{3} \mathrm{COCH}_{3}+\mathrm{CO}_{2}+\mathrm{H}_{2} \mathrm{O} \rightarrow 2 \mathrm{CH}_{3} \mathrm{COO}^{-}+2 \mathrm{H}^{+} \\
\left(\Delta G^{\circ \prime}=-25.8 \mathrm{~kJ} \text { per mol }\right) \\
2 \mathrm{CH}_{3} \mathrm{COO}^{-}+2 \mathrm{H}^{+} \rightarrow 2 \mathrm{CH}_{4}+2 \mathrm{CO}_{2} \\
\left(\Delta G^{\circ \prime}=-71.8 \mathrm{~kJ} \text { per mol }\right) \\
\mathrm{CH}_{3} \mathrm{COCH}_{3}+\mathrm{H}_{2} \mathrm{O} \rightarrow 2 \mathrm{CH}_{4}+\mathrm{CO}_{2} \\
\left(\Delta G^{\circ \prime}=-97.6 \mathrm{~kJ} \text { per mol }\right)
\end{gathered}
$$

Although in this case all partial reactions are exergonic under standard conditions, the primary fermenting bacterium depends on the methanogenic partner, and acetone degradation in the mixed culture is substantially impaired in the presence of acetylene as an inhibitor of methanogens (85). Experiments with the primary acetone-fermenting bacterium in dialysis cultures revealed that accumulation of acetate at concentrations higher than $10 \mathrm{mM}$ inhibited growth and acetone degradation (86). Under these conditions, the free energy available to the acetone fermenter is still in the range of $-40 \mathrm{~kJ}$ per mol. If the observed inhibition is caused by reaction thermodynamics, this appears to be the minimum energy quantum that these bacteria need for substrate turnover. Since acetone metabolism by these bacteria starts with an endergonic carboxylation reaction, this might be the amount of energy that they need to invest into this primary substrate activation reaction, probably through a membrane-associated enzyme system (29). Unfortunately, the acetone-fermenting bacterium was not obtained in pure culture, and hence detailed studies on its biochemistry and energetics could not be performed.

\section{HOMOACETOGENIC CONVERSIONS AND THE EFFECT OF TEMPERATURE}

Under standard conditions, methanogenic hydrogen oxidation yields more energy than homoacetogenic hydrogen oxidation (Table 1), and one would therefore assume that homoacetogens have little chance to compete successfully against methanogens for hydrogen at limiting concentrations. The function of homoacetogens in the complex electron flow scheme depicted in Fig. 1 remains unclear, therefore, and the general assumption is that they take advantage of their metabolic versatility, which allows them to compete with several partners of various metabolic types and consume two or more substrates simultaneously (96). Such simultaneous utilization of more than one substrate may increase the effective affinity

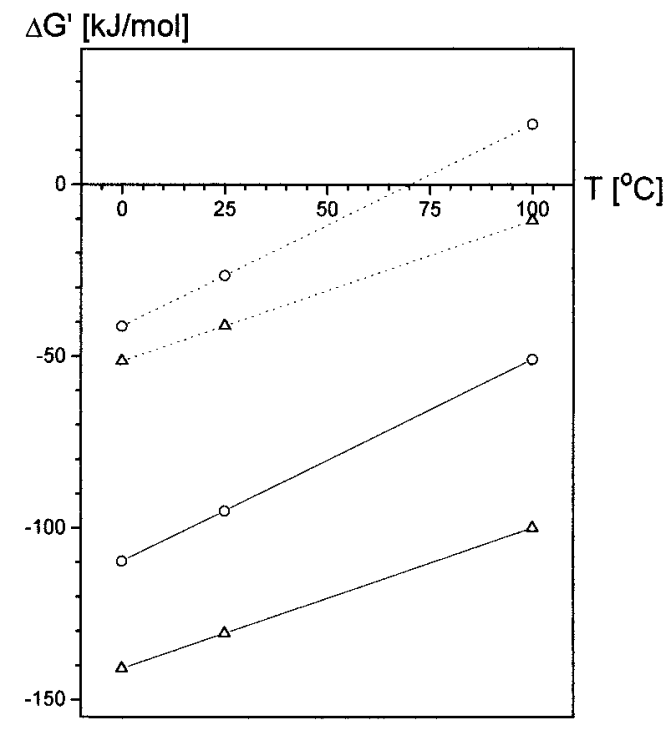

FIG. 13. Temperature dependence of the free energy change in anaerobic hydrogen and acetate metabolism, calculated from the van't Hoff equation with data from references 21,28 , and 65 . Solid lines, standard conditions (1 M concentrations, $10^{5} \mathrm{~Pa}$ pressure); dashed lines, the same for $10 \mathrm{~Pa}$ of hydrogen and $0.3 \times 10^{5} \mathrm{~Pa}$ of $\mathrm{CO}_{2} . \bigcirc, 4 \mathrm{H}_{2}+2 \mathrm{CO}_{2} \rightarrow \mathrm{CH}_{3} \mathrm{COO}^{-}+\mathrm{H}^{+}+2 \mathrm{H}_{2} \mathrm{O} ; \triangle, 4 \mathrm{H}_{2}$ $+\mathrm{CO}_{2} \rightarrow \mathrm{CH}_{4}+2 \mathrm{H}_{2} \mathrm{O}$.

for every single substrate, as studies with Escherichia coli in continuous cultures with multiple substrate supply have proven $(38,69)$. However, there are exceptional situations in which homoacetogens may definitively outcompete methanogens in their function as hydrogen consumers in sulfate-poor anoxic environments. One such situation involves slightly acidic lake sediments such as that of Knaack Lake, Wis., where the total electron flow at $\mathrm{pH} 6.1$ goes through the acetate pool and no methane is formed by direct $\mathrm{CO}_{2}$ reduction (84). Obviously, hydrogen-oxidizing methanogens do not perform sufficiently under these conditions. Thus, homoacetogens take over their function, but only at low acetate concentrations (at $10 \mathrm{~Pa}^{\circ} \mathrm{H}_{2}$ and $10 \mu \mathrm{M}$ acetate, homoacetogenic hydrogen oxidation yields a $\Delta G$ of $-26 \mathrm{~kJ}$ per mol of acetate [Fig. 13]) which must be maintained by aceticlastic methanogens.

Temperature is a further effector which improves the ability of homoacetogens to compete successfully against methanogens for hydrogen. At temperatures lower than $20^{\circ} \mathrm{C}$, homoacetogens appear to take over significant parts of hydrogen oxidation in paddy soil and lake sediments $(21,23)$. The known species of hydrogen-oxidizing methanogens are not significantly active at such temperatures (145), and homoacetogens appear to be less restricted in this respect. Dominance of homoacetogenesis in the total electron flow is even more strongly expressed in tundra wetland soils at temperatures lower than $10^{\circ} \mathrm{C}(62)$. This effect becomes understandable from an investigation of the temperature dependence of hydrogendependent methanogenesis and homoacetogenesis (Fig. 13). At hydrogen partial pressures lower than $10 \mathrm{~Pa}$ and acetate concentrations of $10 \mu \mathrm{M}$, homoacetogenesis reaches the same energy gain at $5^{\circ} \mathrm{C}$ as hydrogen-dependent methanogenesis does at $35^{\circ} \mathrm{C}$. Thus, the general scheme of electron flow in methanogenic environments (Fig. 1) has to be modified for slightly acidic or for low-temperature habitats as far as they have been examined (Fig. 14): under these conditions, there is no significant hydrogen-dependent methanogenesis (group 2), and the electrons flow nearly exclusively via acetogenesis and 


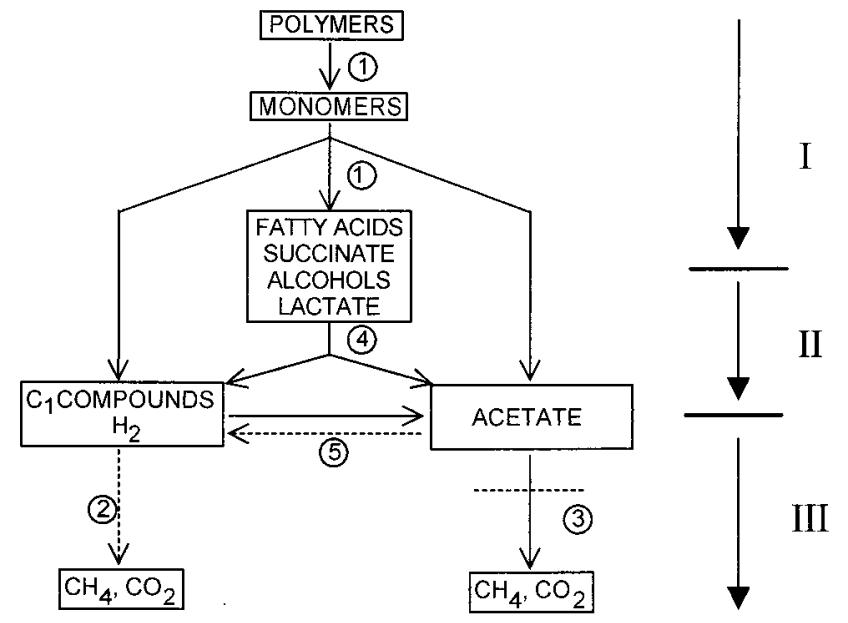

FIG. 14. Carbon and electron flow through the various trophic groups of microorganisms involved in the methanogenic degradation of complex organic matter, as modified for low- and high-temperature habitats. Groups of bacteria involved: 1 , primary fermenting bacteria; 2 , hydrogen-oxidizing methanogens; 3 , acetate-cleaving methanogens; 4 , secondary fermenting ("syntrophic") bacteria; 5 , homoacetogenic bacteria. I, II, and III, steps in degradation.

aceticlastic methanogenesis (groups 5 and 3; solid lines in Fig. 14).

The opposite situation emerges at high-temperature habitats, as already discussed above in the context of syntrophic acetate oxidation: under these conditions, aceticlastic methanogenesis becomes less significant, homoacetogenesis can operate in the opposite direction, and the electron flow goes from acetate through the $\mathrm{C}_{1}$ pool and hydrogen toward methane (groups 5 and 2; dashed lines in Fig. 14). Thus, the general flow scheme in Fig. 1 represents an intermediate situation that probably describes the situation of a sewage sludge digestor correctly but has to be modified for high- and low-temperature situations in the way indicated. The temperature dependence of the respective reaction energetics (Fig. 12 and 13) provides a thermodynamic basis to explain that either alternative shows advantages under the respective conditions. However, it does not explain why hydrogen-oxidizing methanogens do not operate at low temperature or why aceticlastic methanogens do so less frequently at high temperature, although both processes are possible under these conditions as well.

\section{METABOLITE TRANSFER AND THE ADVANTAGE OF AGGREGATION}

The separation of metabolic functions and their distribution within metabolically different microorganisms, i.e., substrate oxidation and hydrogen formation in one organism and hydrogen oxidation and $\mathrm{CO}_{2}$ reduction in the other organism, is a rather unusual strategy that we do not observe, at least not to this extent, in oxic environments. It may have its advantages because it allows a high degree of metabolic specialization to the single organisms concerned, which requires very little biochemical investment into refined regulation of metabolism. However, the metabolic efficiency of such cooperating communities depends on the efficiency of metabolite transfer between the partners involved; the flux of, e.g., hydrogen between the hydrogen-forming fermenter and the hydrogen-consuming methanogen is inversely proportional to the distance between the two (99). Optimal metabolite transfer can be achieved best with the two partners in close contact, i.e., directly attached to each other, forming an aggregate or floc. Such flocs form preferentially in anaerobic digestors in which fatty acids are degraded, although the establishment of stable floc formation may require substantial times, sometimes even months after start-up (70). Indirect evidence of aggregate formation in sediments and sludges has been obtained on the basis of hydrogen exchange measurements $(22,24)$ and has been discussed in more detail elsewhere (95).

Efforts to synthesize stable aggregates of microbiologically defined composition from pure cultures have been made, and their success depended very specifically on the type of partners used: butyrate-degrading aggregates with only two partners were stable only with Methanobacterium formicicum, not with Methanospirillum hungatei, whereas propionate-degrading granules depended on the additional presence of an acetate-dgrading partner (140). In suspended cultures, $M$. hungatei is often the dominant hydrogen utilizer, but it is obviously not the ideal partner for the formation of efficient granules. This experiment demonstrates again that our enrichment and cultivation techniques greatly influence the results obtained and may give a rather incorrect picture of the situation prevailing in the natural or seminatural system. The composition and stability of the formed granules are further influenced by the fact that methanogenic granules in waste-degrading reactors have to deal with mixed substrate supplies which add further microbial constituents, including, e.g., sulfate-reducing bacteria, to the architecture of the resulting granule (137). In any case, optimal cooperation will be secured in granules in which the partner organisms are randomly mixed to near homogeneity rather than in situations in which the partners form "nests" of identical subpopulations (Fig. 15).

A basic problem remains in that each partner bacterium multiplies and produces offspring only of its own kind. Thus, the situation in Fig. 15a will change after several generations into one similar to that in Fig. 15b, and the efficiency of metabolite transfer will decrease with the age of the aggregates unless there are ways of internal mixing of the aggregates. The use of thin sections of methanogenic granules has demonstrated examples of fully mixed as well as of nest structures (36), and similar pictures were recently obtained with thin sections in which the partner bacteria could be identified by RNA-directed gene probes (51). The dynamics of growth and internal structure development in such aggregates could be an interesting object of future research now that gene probes are available to provide excellent tools for direct in situ identification of the various microbial components involved.

\section{METHANOGENS AS ENDOSYMBIOTIC PARTNERS OF PROTOZOA}

The function of the primary fermenting bacteria (group 1) in the conversion of complex organic matter to methane and $\mathrm{CO}_{2}$ (Fig. 1) may be taken over by eukaryotic organisms. Anaerobic fungi, ciliates, and flagellates which thrive in entirely anoxic environments under reducing conditions are known (42), and some of them are extremely oxygen sensitive. Since aerobic respiration is not possible in such habitats, anaerobic protozoa do not contain mitochondria. Instead, intracellular organelles which release hydrogen and have been called hydrogenosomes are present. The metabolism of these protozoa is fermentative; particles, especially bacterial cells, are ingested into food vacuoles and digested by hydrolysis and further fermentation, and acetate is probably the most important fermentation product; however, experimental proof of this assumption is lacking.

Anaerobic protozoa can be associated with symbiotic methanogens, either extracellularly or intracellularly. Ciliates living in strictly anoxic, eutrophic sediments carry methanogenic 
a

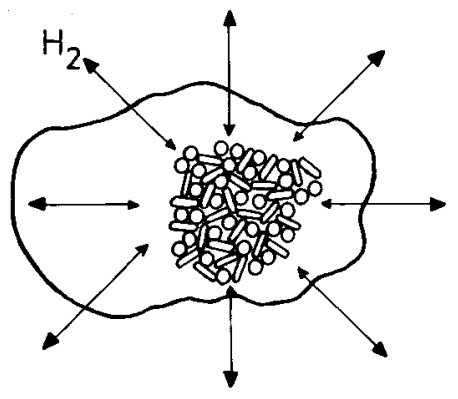

b

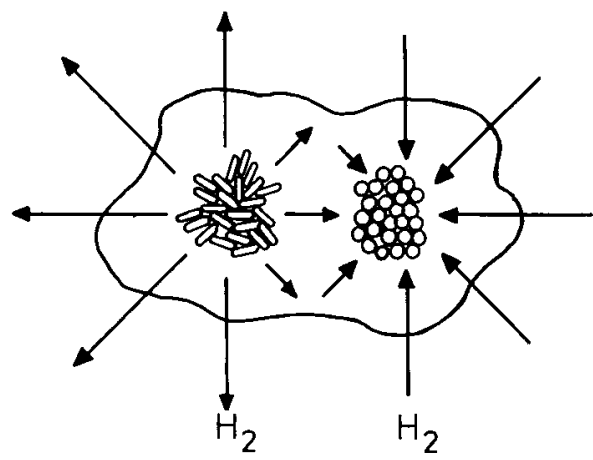

FIG. 15. Exchange of hydrogen in anaerobic microbial flocs containing a homogeneously mixed community of hydrogen producers and consumers (a) or hydrogen producers and consumers in spatially separated nests (b). The thinner arrows for hydrogen release in panel a indicate that far less exchange with the surrounding medium should be expected than in the situation shown in panel $b$. Reprinted from reference 95 with permission.

partner bacteria inside the cell $(124,125)$, often closely associated with the hydrogenosomes. The advantage of this cooperation with hydrogenotrophic methanogens for the protozoan host is obvious. Removal of hydrogen and maintenance of a low hydrogen and formate concentration in the cell allow the fermentation of complex organic matter mainly to acetate and $\mathrm{CO}_{2}$. Thus, wasted conversion of organic precursors into reduced end products such as ethanol, fatty acids, etc., can be avoided, and the fermenting protozoan obtains a maximum ATP yield by fermentation. The symbiotic methanogen takes over part of the function of mitochondria in aerobic higher cells: reducing equivalents are removed by the symbiotic partner, and the eukaryotic host cell runs a fermentative metabolism with a maximum ATP yield.

It is assumed that the hydrogen released by hydrogenosomes stems mainly from pyruvate oxidation to acetyl-CoA (the pyruvate synthase reaction [82]). Hydrogenosomes contain this enzyme, as well as ferredoxin and hydrogenase. In some cases, especially with the larger types of anaerobic protozoa, close associations of methanogenic endosymbionts with hydrogenosomes have been observed. Smaller protozoa may also achieve the same effect of hydrogen release with extracellular partner bacteria, because the diffusion distance to the surface may be short enough. The same applies to the rumen ciliates, which, in their comparably rich habitat, cooperate only occasionally with symbiotic partners on their cell surface (117).

The hydrogenosome and methanogenic endosymbiont together form a functional entity that replaces mitochondria to some extent in a strictly anoxic habitat. In some cases, especially with the comparably big ciliates such as Plagiopyla frontata, hydrogenosomes and methanogens are organized in an alternating sandwich arrangement that allows optimal hydrogen transfer in highly refined structures (42). It has been speculated that the hydrogenosomes of strictly anaerobic protozoa have evolved from the mitochondria of their aerobic predecessors; other speculations assume a relationship of hydrogenosomes to clostridia. The high structural development of hydrogenosomes in some of the protozoa studied may suggest that such arrangements could also operate in the transfer of hydrogen from less easily available electron donors than the pyruvate synthase system represents. Unfortunately, detailed studies on the cooperation of methanogenic endosymbionts with their protozoan hosts have been hampered so far by extreme difficulties in handling defined cultures of strictly anaerobic protozoa.

\section{MODELLING OF SYNTROPHIC OXIDATION PROCESSES}

Since methanogenic degradation of fatty acids is one of the key processes in the technical treatment of sewage sludge and high-load wastewaters, models of the methanogenic conversion efficiency were developed rather early and have been applied to technical systems on a rather empirical basis. These models are based, in most cases, on a Michaelis-Menten approach that assumes a basically irreversible reaction process. Surprisingly, these models did not sufficiently take into account the reaction equilibria and overlooked the problem of thermodynamic end product inhibition, which is so intrinsically important for an understanding of these processes. A new effort in modelling these processes on the basis of the thermodynamics of the underlying reaction has been made recently (55), which appears to describe experimental data much better than did earlier efforts. Thus, as always, modelling a complex process is substantially improved if a structural understanding of the underlying processes involved is added to the simple empirical description of the gross process.

\section{CONCLUSIONS}

The energetics of syntrophic fatty acid and alcohol-oxidizing processes represent exciting examples of energy metabolism based on the smallest energy quantum that, to our present understanding, can be exploited by living cells. This minimum amount of energy which can be converted into ATP in the living cell is in the range of $-20 \mathrm{~kJ}$ per reaction, and this is exactly the amount of energy available to the respective partners in most of the degradation processes discussed here. Models of metabolic cooperation and energy sharing between syntrophic partners can be based on this assumption, and experimental evidence of reversed electron transport systems to balance the energy requirements for hydrogen release have been obtained in several instances.

Whether hydrogen or formate is the electron carrier between the partner organisms remains an open question. There are good indications in several instances that both carriers may operate simultaneously. The energetic equivalence of both channel systems prevents their use separately for electrons of different redox potentials. A clean experimental analysis of this problem is hampered by the fast exchange between them in several anaerobic bacteria, which also precludes tracer experiments, and by the experimental difficulties in quantifying formate at the concentrations relevant to the redox processes involved. In the cases of fatty acid and benzoate degradation, acetate transfer also interferes with the total transformation energetics.

Recent studies on the biochemistry of syntrophic fatty acid 
oxidizers revealed that these bacteria are by no means "primitive" but actually are admirable creatures from the point of view of energy conservation and efficient energy utilization. Most of these bacteria grow in simple mineral media and synthesize all their cellular components on the basis of only the minimum quantum of energy which can be exploited by living cells; they are spectacular examples of how diligently nature has organized the components of global energy flux in environments where very little energy is available to the living inhabitants.

\section{ACKNOWLEDGMENTS}

This article is based on other reviews written recently on the same or related subjects (95-97). I am grateful to Norbert Pfennig, Fritz Widdel, Rudolf Thauer, Marvin P. Bryant, Ralph Wolfe, Ralf Conrad, and Alfons J. M. Stams for numerous fruitful discussions about the biology and energetics of syntrophic anaerobes, and I thank my former and present coworkers, especially Christina (Dörner) Wallrabenstein, Michael Friedrich, Elisabeth Hauschild, and Ludger Schöcke, for their dedicated work on these extremely fastidious bacteria. Thanks are due to Ludger Schöcke as well for his help in the processing of the figures and for reference suggestions.

The experimental background of this contribution as performed in my laboratory was supported by grants from the Deutsche Forschungsgemeinschaft, Bonn, Germany, and the Bundesministerium für Forschung und Technologie, Bonn, Germany, through the research programme "Biologische Wasserstoffgewinnung."

\section{REFERENCES}

1. Ahring, B. K., and P. Westermann. 1987. Thermophilic anaerobic degradation of butyrate by a butyrate-utilizing bacterium in coculture and triculture with methanogenic bacteria. Appl. Environ. Microbiol. 53:429-433.

2. Ahring, B. K., and P. Westermann. 1988. Product inhibition of butyrate metabolism by acetate and hydrogen in a thermophilic coculture. Appl. Environ. Microbiol. 54:2393-2397.

3. Auburger, G., and J. Winter. 1992. Purification and characterization of benzoyl CoA ligase from a syntrophic, benzoate-degrading, anaerobic mixed culture. Appl. Microbiol. Biotechnol. 37:789-795.

4. Badziong, W., and R. K. Thauer. 1980. Vectorial electron transport in Desulfovibrio vulgaris (Marburg) growing on hydrogen plus sulfate as sole energy source. Arch. Microbiol. 125:167-174.

5. Barker, H. A. 1936. On the biochemistry of the methane fermentation. Arch. Microbiol. 7:404-419.

6. Barker, H. A. 1940. Studies upon the methane fermentation. IV. The isolation and culture of Methanobacterium omelianskii. Antonie Leeuwenhoek 6:201-220.

7. Beaty, P. S., and M. J. McInerney. 1987. Growth of Syntrophomonas wolfei in pure cultures on crotonate. Arch. Microbiol. 147:389-393.

8. Beaty, P. S., and M. J. McInerney. 1989. Effect of organic acid anions on the growth and metabolism of Syntrophomonas wolfei in pure culture and in defined consortia. Appl. Environ. Microbiol. 55:977-983.

9. Beaty, P. S., N. Q. Wofford, and M. J. McInerney. 1987. Separation of Syntrophomonas wolfei from Methanospirillum hungatei in syntrophic cocultures by using Percoll gradients. Appl. Environ. Microbiol. 53:1183-1185.

10. Ben-Bassat, A., R. Lamed, and J. G. Zeikus. 1981. Ethanol production by thermophilic bacteria: metabolic control of end product formation in Thermoanaerobium brockii. J. Bacteriol. 146:192-199.

11. Biebl, H., and N. Pfennig. 1978. Growth yields of green sulfur bacteria in mixed cultures with sulfur and sulfate reducing bacteria. Arch. Microbiol. 117:9-16.

12. Blaut, M. 1994. Metabolism of methanogens. Antonie Leeuwenhoek 66: 187-208.

13. Bleicher, K., and J. Winter. 1994. Formate production and utilization by methanogens and by sewage sludge consortia-interference with the concept of interspecies formate transfer. Appl. Microbiol. Biotechnol. 40:910 915 .

14. Boone, D. R., and M. P. Bryant. 1980. Propionate-degrading bacterium, Syntrophobacter wolinii sp. nov. gen. nov., from methanogenic ecosystems. Appl. Environ. Microbiol. 40:626-632.

15. Boone, D. R., R. L. Johnson, and Y. Liu. 1989. Diffusion of the interspecies electron carriers $\mathrm{H}_{2}$ and formate in methanogenic ecosystems, and implications in the measurement of $\mathrm{K}_{\mathrm{M}}$ for $\mathrm{H}_{2}$ or formate uptake. Appl. Environ. Microbiol. 55:1735-1741.

16. Boone, D. R., R. L. Johnson, and Y. Liu. 1989. Microbial ecology of interspecies hydrogen and formate transfer in methanogenic ecosystems, p. 450-453. In T. Hattori, Y. Ishida, Y. Maruyama, R. Y. Morita, and A.
Uchida (ed.), Recent advances in microbial ecology. Japan Scientific Societies Press, Tokyo, Japan.

17. Bryant, M. P. 1979. Microbial methane production-theoretical aspects. J. Anim. Sci. 48:193-201.

18. Bryant, M. P., E. A. Wolin, M. J. Wolin, and R. S. Wolfe. 1967. Methanoba cillus omelianskii, a symbiotic association of two species of bacteria. Arch. Mikrobiol. 59:20-31.

19. Bryant, M. P., L. L. Campbell, C. A. Reddy, and M. R. Crabill. 1977. Growth of Desulfovibrio in lactate or ethanol media low in sulfate in association with $\mathrm{H}_{2}$-utilizing methanogenic bacteria. Appl. Environ. Microbiol. 33:1162-1169.

20. Buckel, W., and R. Semmler. 1983. Purification, characterization, and reconstitution of glutaconyl-CoA decarboxylase, a biotin-dependent sodium pump from anaerobic bacteria. Eur. J. Biochem. 136:427-434.

21. Conrad, R., and B. Wetter. 1990. Influence of temperature on energetics of hydrogen metabolism in homoacetogenic, methanogenic, and other anaerobic bacteria. Arch. Microbiol. 155:94-98.

22. Conrad, R., B. Schink, and T. J. Phelps. 1986. Thermodynamics of $\mathbf{H}_{2}$ consuming and $\mathrm{H}_{2}$-producing metabolic reactions in diverse methanogenic environments under in situ conditions. FEMS Microbiol. Ecol. 38:353-360.

23. Conrad, R., F. Bak, H. J. Seitz, B. Thebrath, H. P. Mayer, and H. Schütz 1989. Hydrogen turnover by psychrotrophic homoacetogenic and mesophilic methanogenic bacteria in anoxic paddy soil and lake sediment. FEMS Microbiol. Ecol. 62:285-294.

24. Conrad, R., T. J. Phelps, and J. G. Zeikus. 1985. Gas metabolism evidence in support of the juxtaposition of hydrogen-producing and methanogenic bacteria in sewage sludge and lake sediments. Appl. Environ. Microbiol. 50:595-601.

25. Cypionka, H., and W. Dilling. 1986. Intracellular localization of the hydrogenase in Desulfotomaculum orientis. FEMS Microbiol. Lett. 36:257-260.

26. Deppenmeier, U., V. Müller, and G. Gottschalk. 1996. Pathways of energy conservation in methanogenic archaea. Arch. Microbiol. 165:149-163.

27. Diekert, G., and G. Wohlfahrt. 1994. Metabolism of homoacetogens. Antonie Leeuwenhoek 66:209-221.

28. Dimroth, K. 1983. Thermochemische Daten organischer Verbindungen, p. 997-1038. In D'ans-Lax Taschenbuch für Chemiker und Physiker, Bd. 2. Springer-Verlag, Berlin, Germany.

29. Dimroth, P. 1987. Sodium transport decarboxylases and other aspects of sodium ion cycling in bacteria. Microbiol. Rev. 51:320-340.

30. Dolfing, J. 1988. Acetogenesis, p. 417-468. In A. J. B. Zehnder (ed.) Biology of anaerobic microorganisms. John Wiley \& Sons, Inc., New York, N.Y

31. Dong, X., and A. J. M. Stams. 1995. Evidence for $\mathrm{H}_{2}$ and formate formation during syntrophic butyrate and propionate degradation. Anaerobe 1:35-39.

32. Dong, X., and A. J. M. Stams. 1995. Localization of enzymes involved in $\mathrm{H}_{2}$ and formate metabolism in Syntrophospora bryantii. Antonie Leeuwenhoek 67:345-350.

33. Dong, X., C. M. Plugge, and A. J. M. Stams. 1994. Anaerobic degradation of propionate by a mesophilic acetogenic bacterium in co- and triculture with different methanogens. Appl. Environ. Microbiol. 60:2834-2838.

34. Dong, X., G. Cheng, and A. J. M. Stams. 1994. Butyrate oxidation by Syntrophospora bryantii in coculture with different methanogens and in pure culture with pentenoate as electron acceptor. Appl. Microbiol. Biotechnol. 42:647-652.

35. Dörner, C. 1992. Biochemie und Energetik der Wasserstofffreisetzung in der syntrophen Vergärung von Fettsäuren und Benzoat. Ph.D. thesis. Universität Tübingen, Tübingen, Germany.

36. Dubourguier, H. C., G. Prensier, and G. Albagnac. 1988. Structure and microbial activities of granular anaerobic sludge, p. 18-33. In G. Lettinga et al. (ed.), Granular anaerobic sludge: microbiology and technology. Pudoc, Wageningen, The Netherlands.

37. Dwyer, D. F., E. Weeg-Aerssens, D. R. Shelton, and J. M. Tiedje. 1988 Bioenergetic conditions of butyrate metabolism by a syntrophic, anaerobic bacterium in coculture with hydrogen-oxidizing methanogenic and sulfidogenic bacteria. Appl. Environ. Microbiol. 54:1354-1359.

38. Egli, T. 1995. The ecological and physiological significance of the growth of heterotrophic microorganisms with mixtures of substrates. Adv. Microb. Ecol. 14:305-386.

39. Eichler, B., and B. Schink. 1986. Fermentation of primary alcohols and diols, and pure culture of syntrophically alcohol-oxidizing anaerobes. Arch. Microbiol. 143:60-66.

40. Evans, W. C., and G. Fuchs. 1988. Anaerobic degradation of aromatic compounds. Annu. Rev. Microbiol. 42:289-317.

41. Ferguson, S. J., and M. C. Sorgato. 1982. Proton electrochemical gradients and energy-transduction processes. Annu. Rev. Biochem. 51:185-217.

42. Finlay, B. J., and T. Fenchel. 1992. Methanogens and other bacteria as symbionts of free-living anaerobic ciliates. Symbiosis 14:375-390.

42a.Friedrich, M. Unpublished data.

43. Friedrich, M., and B. Schink. 1993. Hydrogen formation from glycolate driven by reversed electron transport in membrane vesicles of a syntrophic glycolate-oxidizing bacterium. Eur. J. Biochem. 217:233-240.

44. Friedrich, M., and B. Schink. 1995. Electron transport phosphorylation 
driven by glyoxylate respiration with hydrogen as electron donor in membrane vesicles of a glyoxylate-fermenting bacterium. Arch. Microbiol. 163: 268-275.

45. Friedrich, M., U. Laderer, and B. Schink. 1991. Fermentative degradation of glycolic acid by defined syntrophic cocultures. Arch. Microbiol. 156:398-404.

46. Friedrich, M., N. Springer, W. Ludwig, and B. Schink. Phylogenetic position of Desulfofustis glycolicus gen. nov. sp. nov. and Syntrophobotulus glycolicus gen. nov. sp. nov., two strict anaerobes growing with glycolic acid. Int. J. Syst. Bacteriol. 46:1065-1069.

46a.Fuchs, G. Personal communication.

47. Fuchs, G. M., E. S. Mohamed, U. Altenschmidt, J. Roch, A. Lach, R. Brackmann, C. Lockmeyer, and B. Oswald. 1994. Biochemistry of anaerobic biodegradation of aromatic compounds, p. 513-553. In C. Ratledge (ed.), Biochemistry of microbial degradation. Kluwer Academic Publishers, Dordrecht, The Netherlands.

48. Fukuzaki, S., N. Nishio, M. Shobayashi, and S. Nagai. 1990. Inhibition of the fermentation of propionate to methane by hydrogen, acetate, and propionate. Appl. Environ. Microbiol. 56:719-723.

49. Harmsen, H. J. M., H. M. P. Kengen, A. D. L. Akkermans, and A. J. M. Stams. 1995. Phylogenetic analysis of two syntrophic propionate-oxidizing bacteria in enrichment cultures. Syst. Appl. Microbiol. 18:67-73.

50. Harmsen, H., B. Wullings, A. D. L. Akkermans, W. Ludwig, and A. J. M. Stams. 1993. Phylogenetic analysis of Syntrophobacter wolinii reveals a relationship with sulfate-reducing bacteria. Arch. Microbiol. 160:238-240.

51. Harmsen, H. J. M., H. M. P. Kengen, A. D. L. Akkermans, A. J. M. Stams, and W. M. de Vos. 1996. Detection and localization of syntrophic propionate-oxidizing bacteria in granular sludge by in situ hybridization using $16 \mathrm{~S}$ rRNA-based oligonucleotide probes. Appl. Environ. Microbiol. 62: $1656-1663$

52. Hauschild, E. 1997. Biochemie und Energetik der syntrophen Oxidation von Ethanol durch Pelobacter acetylenicus. Ph.D. thesis. Universität Konstanz, Konstanz, Germany.

53. Henson, J. M., and P. H. Smith. 1985. Isolation of a butyrate-utilizing bacterium in coculture with Methanobacterium thermoautotrophicum from a thermophilic digester. Appl. Environ. Microbiol. 49:1461-1466.

54. Hoehler, T. M., M. J. Alperin, D. B. Albert, and C. S. Martens. 1994. Field and laboratory studies of methane oxidation in an anoxic marine sediment: evidence for a methanogen-sulfate reducer consortium. Global Biogeochem. Cycles 8:451-463.

55. Hoh, C. Y., and R. Cord-Ruwisch. 1996. A practical kinetic model that considers endproduct inhibition in anaerobic digestion processes by including the equilibrium constant. I. Model formulation. Biotechnol. Bioeng. 51:597-604.

56. Hopkins, B. T., M. McInerney, and V. Warikoo. 1995. Evidence for an anaerobic syntrophic benzoate degradation threshold and isolation of the syntrophic benzoate degrader. Appl. Environ. Microbiol. 61:526-530.

57. Houwen, F. P., C. Dijkema, C. H. H. Schoenmakers, A. J. M. Stams, and A. J. B. Zehnder. 1987. 13C-NMR study of propionate degradation by a methanogenic coculture. FEMS Microbiol. Lett. 41:269-274.

58. Houwen, F. P., J. Plokker, A. J. M. Stams, and A. J. B. Zehnder. 1990. Enzymatic evidence for involvement of the methylmalonyl-CoA pathway in propionate oxidation by Syntrophobacter wolinii. Arch. Microbiol. 155:52-55.

59. Iversen, N., and B. B. Jørgensen. 1985. Anaerobic methane oxidation rates at the sulfate-methane transition in marine sediments from Kattegat and Skagerrak (Denmark). Limnol. Oceanogr. 30:944-955.

60. Koch, J., W. Eisenreich, A. Bacher, and G. Fuchs. 1993. Products of enzymatic reduction of benzoyl-CoA, a key reaction in anaerobic aromatic metabolism. Eur. J. Biochem. 211:649-661.

61. Koch, M., J. Dolfing, K. Wuhrmann, and A. J. B. Zehnder. 1983. Pathway of propionate degradation by enriched methanogenic cultures. Appl. Environ. Microbiol. 45:1411-1414.

62. Kotsyurbenko, O. R., A. N. Nozhevnikova, T. I. Soloviova, and G. A. Zavarzin. 1996. Methanogenesis at low temperatures by microflora of tundra wetland soil. Antonie Leeuwenhoek 69:75-86.

63. Kröger, A., V. Geisler, E. Lemma, F. Theis, and R. Lenger. 1992. Bacterial fumarate respiration. Arch. Microbiol. 158:311-314.

64. Lack, A., and G. Fuchs. 1994. Evidence that phenol phosphorylation to phenylphosphate is the first step in anaerobic phenol metabolism in a denitrifying Pseudomonas sp. Arch. Microbiol. 161:132-139.

65. Lange, N. A. 1967. Handbook of chemistry. McGraw-Hill Book Co., New York, N.Y.

66. Lee, M. J., and S. H. Zinder. 1988. Isolation and characterization of a thermophilic bacterium which oxidizes acetate in syntrophic association with a methanogen and which grows acetogenically on $\mathrm{H}_{2}-\mathrm{CO}_{2}$. Appl. Environ. Microbiol. 54:124-129.

67. Lee, M. J., and S. H. Zinder. 1988. Carbon monoxide pathway enzyme activities in a thermophilic anaerobic bacterium grown acetogenically and in a syntrophic acetate-oxidizing coculture. Arch. Microbiol. 150:513-518.

68. Lee, M. J., and S. H. Zinder. 1988. Hydrogen partial pressures in a thermophilic acetate-oxidizing methanogenic cocultures. Appl. Environ. Microbiol. 54:1457-1461.

69. Lendenmann, U., M. Snozzi, and T. Egli. 1996. Kinetics of the simultaneous utilization of sugar mixtures by Escherichia coli in continuous culture. Appl. Environ. Microbiol. 62:1493-1499.

70. Lettinga, G., A. J. B. Zehnder, J. T. C. Grotenhuis, and L. W. Hulshoff Pol 1988. Granular anaerobic sludge: microbiology and technology. Pudoc, Wageningen, The Netherlands.

71. Maloney, P. C. 1983. Relationship between phosphorylation potential and electrochemical $\mathrm{H}^{+}$gradient during glycolysis in Streptococcus lactis. J. Bacteriol. 153:1461-1470.

72. Matthies, C., and B. Schink. 1992. Reciprocal isomerization of butyrate and isobutyrate by strain WoGl3, and methanogenic isobutyrate degradation by a defined triculture. Appl. Environ. Microbiol. 58:1435-1439.

73. Matthies, C., and B. Schink. 1993. Anaerobic degradation of long-chain dicarboxylic acids by methanogenic enrichment cultures. FEMS Microbiol. Lett. 111:177-182.

74. McInerney, M. J. 1986. Transient and persistent associations among prokaryotes, p. 293-338. In J. S. Poindexter and E. R. Leadbetter (ed.), Bacteria in nature, vol. 2. Plenum Press, New York, N.Y.

75. McInerney, M. J. 1988. Anaerobic degradation of proteins and lipids, p. 373-415. In A. J. B. Zehnder (ed.), Biology of anaerobic microorganisms. John Wiley \& Sons, Inc., New York, N.Y.

76. McInerney, M. J., and N. Q. Wofford. 1992. Enzymes involved in crotonate metabolism in Syntrophomonas wolfei. Arch. Microbiol. 158:344-349.

77. McInerney, M. J., M. P. Bryant, and N. Pfennig. 1979. Anaerobic bacterium that degrades fatty acids in syntrophic association with methanogens. Arch. Microbiol. 122:129-135.

78. McInerney, M. J., M. P. Bryant, R. B. Hespell, and J. W. Costerton. 1981 Syntrophomonas wolfei gen. nov. sp. nov., an anaerobic, syntrophic, fatty acid-oxidizing bacterium. Appl. Environ. Microbiol. 41:1029-1039.

79. Mitchell, P. 1966. Chemiosmotic coupling in oxidative and photosynthetic phosphorylation. Biol. Rev. Cambridge Philos. Soc. 41:445-502.

80. Mountfort, D. O., and H. F. Kaspar. 1986. Palladium-mediated hydrogenation of unsaturated hydrocarbons with hydrogen gas released during anaerobic cellulose degradation. Appl. Environ. Microbiol. 52:744-750.

81. Mountfort, D. O., and M. P. Bryant. 1982. Isolation and characterization of an anaerobic syntrophic benzoate-degrading bacterium from sewage sludge. Arch. Microbiol. 133:249-256.

82. Müller, M. 1988. Energy metabolism of protozoa without mitochondria Annu. Rev. Microbiol. 42:465-488.

83. Pfennig, N. 1980. Syntrophic mixed cultures and symbiontic consortia with phototrophic bacteria: a review, p. 127-131. In G. Gottschalk et al. (ed.), Anaerobes and anaerobic infections. Fischer, Stuttgart, Germany.

84. Phelps, T. J., and J. G. Zeikus. 1984. Influence of $\mathrm{pH}$ on terminal carbon metabolism in anoxic sediments from a mildly acidic lake. Appl. Environ. Microbiol. 48:1088-1095

85. Platen, H., and B. Schink. 1987. Methanogenic degradation of acetone by an enrichment culture. Arch. Microbiol. 149:136-141.

86. Platen, H., P. H. Janssen, and B. Schink. 1994. Fermentative degradation of acetone by an enrichment culture in membrane-separated culture devices and in cell suspensions. FEMS Microbiol. Lett. 122:27-32.

87. Plugge, C. M., C. Dijkema, and A. J. M. Stams. 1993. Acetyl-CoA cleavage pathway in a syntrophic propionate oxidizing bacterium growing on fumarate in the absence of methanogens. FEMS Microbiol. Lett. 110:71-76.

88. Reeburgh, W. S. 1980. Anaerobic methane oxidation: rate distributions in Skan Bay sediments. Earth Planet. Sci. Lett. 47:345-352.

89. Roy, F., E. Samain, H. C. Dubourgier, and G. Albagnac. 1986. Syntrophomonas sapovorans sp. nov., a new obligately proton reducing anaerobe oxidizing saturated and unsaturated long chain fatty acids. Arch. Microbiol. 145:142-147.

90. Rozanova, E. P., A. S. Galushko, and T. N. Nazina. 1990. An acetate decomposing sulfidogenic syntrophic association, p. 469-470. In J. P. Belaich, M. Bruschi, and J.-L. Garcia (ed.), Microbiology and biochemistry of strict anaerobes involved in interspecies hydrogen transfer. Plenum Press, New York, N.Y.

91. Schink, B. 1984. Fermentation of 2.3-butanediol by Pelobacter carbinolicus sp. nov., and Pelobacter propionicus, sp. nov., and evidence for propionate formation from $\mathrm{C}_{2}$ compounds. Arch. Microbiol. 137:33-41.

92. Schink, B. 1985 . Fermentation of acetylene by an obligate anaerobe, $P e$ lobacter acetylenicus sp. nov. Arch. Microbiol. 142:295-301.

93. Schink, B. 1985. Mechanism and kinetics of succinate and propionate degradation in anoxic freshwater sediments and sewage sludge. J. Gen. Microbiol. 131:643-650.

94. Schink, B. 1990. Conservation of small amounts of energy in fermenting bacteria, p. 63-89. In R. K. Finn and P. Präve (ed.), Biotechnology, focus 2. Hanser Publishers, Munich, Germany.

95. Schink, B. 1991. Syntrophism among prokaryotes, p. 276-299. In A. Balows, H. G. Trüper, M. Dworkin, and K. H. Schleifer (ed.), The prokaryotes, 2nd ed. Springer-Verlag, New York, N.Y.

96. Schink, B. 1994. Diversity, ecology, and isolation of acetogenic bacteria, p 197-235. In H. L. Drake (ed.), Acetogenesis. Chapman \& Hall, New York, N.Y.

97. Schink, B., and M. Friedrich. 1994. Energetics of syntrophic fatty acid degradation. FEMS Microbiol. Rev. 15:85-94. 
98. Schink, B., and M. Stieb. 1983. Fermentative degradation of polyethylene glycol by a new strictly anaerobic gram-negative nonsporeforming bacterium, Pelobacter venetianus sp. nov. Appl. Environ. Microbiol. 45:1905-1913.

99. Schink, B., and R. K. Thauer. 1988. Energetics of syntrophic methane formation and the influence of aggregation, p. 5-17. In G. Lettinga et al. (ed.), Granular anaerobic sludge: microbiology and technology. Pudoc, Wageningen, The Netherlands.

100. Schink, B., A. Brune, and S. Schnell. 1992. Anaerobic degradation of aromatic compounds, p. 219-242. In G. Winkelmann (ed.), Microbial degradation of natural products. VCH Verlagsgesellschaft, Weinheim, Germany.

101. Schmidt, J. E., and B. K. Ahring. 1993. Effects of hydrogen and formate on the degradation of propionate and butyrate in thermophilic granules from an upflow anaerobic sludge blanket reactor. Appl. Environ. Microbiol. 59:2546-2551.

102. Schnürer, A., F. P. Houwen, and B. H. Svensson. 1994. Mesophilic syntrophic acetate oxidation during methane formation by a triculture at high ammonium concentration. Arch. Microbiol. 162:70-74.

102a.Schnürer, A., and B. Schink. Unpublished data.

103. Schnürer, A., B. Schink, and B. H. Svensson. 1996. Clostridium ultunense sp. nov., a mesophilic bacterium oxidizing acetate in syntrophic association with a hydrogenotrophic methanogenic bacterium. Int. J. Syst. Bacteriol 46:1145-1152.

104. Schöcke, L., and B. Schink. Energetics of methanogenic benzoate degradation by Syntrophus gentianae in syntrophic coculture. Microbiology, in press.

105. Schönheit, P., J. Moll, and R. K. Thauer. 1980. Growth parameters $\left(\mathrm{K}_{\mathrm{s}}, \mathrm{v}_{\max }\right.$, $\mathrm{Y}_{\mathrm{s}}$ ) of Methanobacterium thermoautotrophicum. Arch. Microbiol. 127:59-65.

106. Seitz, H.-J., B. Schink, and R. Conrad. 1988. Thermodynamics of hydrogen metabolism in methanogenic cocultures degrading ethanol or lactate. FEMS Microbiol. Lett. 55:119-124.

107. Seitz, H.-J., B. Schink, N. Pfennig, and R. Conrad. 1989. Energetics of syntrophic ethanol oxidation in defined chemostat cocultures. 2. Energy sharing in biomass production. Arch. Microbiol. 155:89-93.

108. Shelton, D. R., and J. M. Tiedje. 1984. Isolation and partial characterization of bacteria in an anaerobic consortium that mineralizes 3-chlorobenzoic acid. Appl. Environ. Microbiol. 48:840-848.

109. Stams, A. J. M. 1994. Metabolic interactions between anaerobic bacteria in methanogenic environments. Antonie Leeuwenhoek 66:271-294.

110. Stams, A. J. M., and X. Dong. 1995. Role of formate and hydrogen in the degradation of propionate and butyrate by defined suspended cocultures of acetogenic and methanogenic bacteria. Antonie Leeuwenhoek 68:281-284.

111. Stams, A. J. M., J. B. van Dijk, C. Dijkema, and C. M. Plugge. 1993. Growth of syntrophic propionate-oxidizing bacteria with fumarate in the absence of methanogenic bacteria. Appl. Environ. Microbiol. 59:1114-1119.

112. Stams, A. J. M., J. T. C. Grotenhuis, and A. J. B. Zehnder. 1989. Structurefunction relationship in granular sludge, p. 440-445. In T. Hattori, Y. Ishida, Y. Maruyama, R. Y. Morita, and A. Uchida (ed.), Recent advances in microbial ecology. Japan Scientific Societies Press, Tokyo, Japan.

113. Stams, A. J. M., K. J. F. Grolle, C. T. M. J. Frijters, and J. B. van Lier. 1992 Enrichment of thermophilic propionate-oxidizing bacteria in syntrophy with Methanobacterium thermoautotrophicum or Methanobacterium thermoformicicum. Appl. Environ. Microbiol. 58:346-352.

114. Stieb, M., and B. Schink. 1985. Anaerobic oxidation of fatty acids by Clostridium bryantii sp. nov., a sporeforming, obligately syntrophic bacterium. Arch. Microbiol. 140:387-390.

115. Stieb, M., and B. Schink. 1986. Anaerobic degradation of isovalerate by a defined methanogenic coculture. Arch. Microbiol. 144:291-295.

116. Stieb, M., and B. Schink. 1989. Anaerobic degradation of isobutyrate by methanogenic enrichment cultures and by a Desulfococcus multivorans strain. Arch. Microbiol. 144:291-295.

117. Stumm, C. K., H. J. Gijzen, and G. D. Vogels. 1982. Association of methanogenic bacteria with ovine rumen ciliates. Br. J. Nutr. 47:95-99.

118. Thauer, R. K., and J. G. Morris. 1984. Metabolism of chemotrophic anaerobes: old views and new aspects, p. 123-168. In D. P. Kelly and N. G. Carr (ed.), The microbe 1984. II. Prokaryotes and eukaryotes. Cambridge University Press, Cambridge, United Kingdom.

119. Thauer, R. K., K. Jungermann, and K. Decker. 1977. Energy conservation in chemotrophic anaerobic bacteria. Bacteriol. Rev. 41:100-180.

120. Thiele, J., and J. G. Zeikus. 1988. Interactions between hydrogen and formate-producing bacteria and methanogens during anaerobic digestion, p. 537-595. In L. E. Erickson and D. Y.-C. Fung (ed.), Handbook on anaerobic fermentations. Marcel Dekker, Inc., New York, N.Y.

121. Thiele, J. H., and J. G. Zeikus. 1988. Control of interspecies electron flow during anaerobic digestion: significance of formate transfer versus hydrogen transfer during syntrophic methanogenesis in flocs. Appl. Environ. Microbiol. 54:20-29.

122. Tholozan, J. L., E. Samain, J. P. Grivet, and G. Albagnac. 1990. Propionate metabolism in a methanogenic enrichment culture. Direct reductive carboxylation and acetogenesis pathways. FEMS Microbiol. Ecol. 73:291-298.

123. Trüper, H. G., and N. Pfennig. 1971. Family of phototrophic green sulfur bacteria: Chlorobiaceae Copeland, the correct family name; rejection of
Chlorobacterium Lauterborn; and the taxonomic situation of the consortium-forming species. Int. J. Syst. Bacteriol. 21:8-10.

124. van Bruggen, J. J. A., C. K. Stumm, and G. D. Vogels. 1983. Symbiosis of methanogenic bacteria and sapropelic protozoa. Arch. Microbiol. 136:89-95.

125. van Bruggen, J. J. A., C. K. Stumm, K. B. Zwart, and G. D. Vogels. 1985. Endosymbiontic methanogenic bacteria of the sapropelic amoeba Mastigella. FEMS Microbiol. Ecol. 31:187-192.

126. van Lier, J. B., K. C. Grolle, C. T. Frijters, A. J. M. Stams, and G. Lettinga. 1993. Effects of acetate, propionate, and butyrate on the thermophilic anaerobic degradation of propionate by methanogenic sludge and defined cultures. Appl. Environ. Microbiol. 59:1003-1011.

127. von Jagow, G., and W. D. Engel. 1980. Struktur und Funktion des energieumwandelnden Systems der Mitochondrien. Angew. Chem. 92:684-700.

128. Wallrabenstein, C., and B. Schink. 1994. Evidence of reversed electron transport involved in syntrophic butyrate and benzoate oxidation by Syntrophomonas wolfei and Syntrophus buswellii. Arch. Microbiol. 162:136-142.

129. Wallrabenstein, C., E. Hauschild, and B. Schink. 1994. Pure culture an cytological properties of Syntrophobacter wolinii. FEMS Microbiol. Lett. 123:249-254.

130. Wallrabenstein, C., E. Hauschild, and B. Schink. 1995. Syntrophobacter pfennigii sp. nov., a new syntrophically propionate-oxidizing anaerobe growing in pure culture with propionate and sulfate. Arch. Microbiol. 164:346-352.

131. Wallrabenstein, C., N. Gorny, N. Springer, W. Ludwig, and B. Schink. 1995. Pure culture of Syntrophus buswellii, definition of its phylogenetic status, and description of Syntrophus gentianae sp. nov. Syst. Appl. Microbiol. 18:62-66.

132. Warikoo, V., M. J. McInerney, J. A. Robinson, and J. M. Suflita. 1996 Interspecies acetate transfer influences the extent of anaerobic benzoate degradation by syntrophic consortia. Appl. Environ. Microbiol. 62:2632.

133. Widdel, F. 1988. Microbiology and ecology of sulfate- and sulfurreducing bacteria, p. 469-585. In A. J. B. Zehnder (ed.), Biology of anaerobic microorganisms. John Wiley \& Sons, Inc., New York, N.Y.

134. Wofford, N. Q., P. S. Beaty, and M. J. McInerney. 1986. Preparation of cell-free extracts and the enzymes involved in fatty acid metabolism in Syntrophomonas wolfei. J. Bacteriol. 167:179-185.

135. Wolin, M. J. 1974. Metabolic interactions among intestinal microorganism Am. J. Clin. Nutr. 27:1320-1328.

136. Wolin, M. J. 1982. Hydrogen transfer in microbial communities, p. 323-356. In A. T. Bull and J. H. Slater (ed.), Microbial interactions and communities, vol. 1. Academic Press, Ltd., London, United Kingdom.

137. Wu, W.-M., M. K. Jain, R. F. Hickey, and J. G. Zeikus. 1991. Characterization of metabolic performance of methanogenic granules treating brewery wastewater: role of sulfate-reducing bacteria. Appl. Environ. Microbiol. 57:3438-3449.

138. Wu, W.-M., R. F. Hickey, M. Jain, and J. G. Zeikus. 1993. Energetics and regulations of formate and hydrogen metabolism by Methanobacterium formicicum. Arch. Microbiol. 159:57-65.

139. Wu, W.-M., M. K. Jain, R. F. Hickey, and J. G. Zeikus. 1994. Anaerobic degradation of normal- and branched-chain fatty acids with four or more carbons to methane by a syntrophic methanogenic triculture. Appl. Environ. Microbiol. 57:2220-2226.

140. Wu, W.-M., M. K. Jain, R. F. Hickey, and J. G. Zeikus. 1996. Formation of fatty acid-degrading, anaerobic granules by defined species. Appl. Environ. Microbiol. 62:2037-2044

141. Wu, W.-M., M. K. Jain, R. F. Hickey, and J. G. Zeikus. Perturbation of syntrophic isobutyrate and butyrate degradation with formate and hydrogen. Biotechnol. Bioeng., in press.

142. Zehnder, A. J. B. 1978. Ecology of methane formation, p. 349-376. In R Mitchell (ed.), Water pollution microbiology, vol. 2. John Wiley \& Sons, Ltd., London, United Kingdom.

143. Zehnder, A. J. B., and T. D. Brock. 1979. Methane formation and methane oxidation by methanogenic bacteria. J. Bacteriol. 137:420-432.

144. Zehnder, A. J. B., K. Ingvorsen, and T. Marti. 1982. Microbiology of methane bacteria, p. 45-68. In D. E. Hughes et al. (ed.), Anaerobic digestion. Elsevier Biomedical Press, Amsterdam, The Netherlands.

145. Zeikus, J. G., and M. Winfrey. 1976. Temperature limitation of methanogenesis in aquatic sediments. Appl. Environ. Microbiol. 31:99-107.

146. Zeikus, J. G. 1977. The biology of methanogenic bacteria. Bacteriol. Rev. 41:514-541.

147. Zhao, H., D. Yang, C. R. Woese, and M. P. Bryant. 1990. Assignment of Clostridium bryantii to Syntrophospora bryantii gen. nov., nov. comb., based on $16 \mathrm{~S}$ rRNA sequence analysis of its crotonate-grown pure culture. Int. J. Syst. Bacteriol. 40:40-44.

148. Zindel, U., W. Freudenberg, M. Rieth, J. R. Andreesen, J. Schnell, and F. Widdel. 1988. Eubacterium acidaminophilum sp. nov., a versatile amino acid-degrading anaerobe producing or utilizing $\mathrm{H} 2$ or formate. Description and enzymatic studies. Arch. Microbiol. 150:254-266.

149. Zinder, S. H., and M. Koch. 1984. Non-aceticlastic methanogenesis from acetate: acetate oxidation by a thermophilic syntrophic coculture. Arch Microbiol. 138:263-272. 